\title{
On the Controlling Mechanism of the Upper Turnover States in the NTC Regime
}

\author{
Weiqi Ji ${ }^{\text {a }}$, Peng Zhao ${ }^{\text {b,c, }, \dagger}$, Tanjin $\mathrm{He}^{\mathrm{d}}$, Xin He ${ }^{\mathrm{a}, \mathrm{d}}$, Aamir Farooq ${ }^{\mathrm{e}}$, Chung K. Law ${ }^{\mathrm{a}, \mathrm{c},{ }^{,}, \downarrow}$ \\ ${ }^{a}$ Center for Combustion Energy, Tsinghua University, Beijing 100084, China \\ ${ }^{\mathrm{b}}$ Department of Mechanical Engineering, Oakland University, Rochester, MI, 48309, USA \\ ${ }^{c}$ Department of Mechanical and Aerospace Engineering, Princeton University, Princeton, NJ \\ 08544, USA \\ ${ }^{\mathrm{d}}$ State Key Laboratory of Automotive Safety and Energy, Tsinghua University, Beijing \\ 100084, China \\ ${ }^{\mathrm{e}}$ Clean Combustion Research Center, Division of Physical Sciences and Engineering, King \\ Abdullah University of Science and Technology, Thuwal 23955-6900, Saudi Arabia \\ *Corresponding authors \\ †Email: pengzhao@ oakland.edu \\ †Email: cklaw@princeton.edu
}




\section{Abstract}

Using $n$-butane, $n$-heptane and iso-octane as representative fuels exhibiting NTC (negative temperature coefficient) behavior, comprehensive computational studies with detailed mechanisms and theoretical analysis were performed to investigate the upper stationary point, denoted as turnover states, on the NTC curve near the higher temperature regime, where the ignition delay $\tau$ exhibits a local maximum. It is found that the global behavior of the turnover states exhibits distinctive thermodynamic and kinetic characteristics under different pressures, in that the ignition delay at the turnover states shows an Arrhenius dependence on the temperature $T$ and an approximate inverse quadratic power law dependence on the pressure $P$. These global behaviors imply that the temperature and pressure of the turnover states are not independent and can be correlated by an Arrhenius dependence, as $\ln P \propto 1 / T$. Further theoretical analyses demonstrate that such turnover states result from the competition between the low-temperature chain branching reactions and the decomposition of the intermediate species, and therefore correspond to a critical value, $\alpha$, of the ratio of $\mathrm{OH}$ production from low-temperature chemistry. In addition, the ignition delay at the turnover state can be well correlated by the analytical expression derived by Peters et al., with the further demonstration that the pressure dependence of the turnover ignition delay mainly result from the $\mathrm{H}_{2} \mathrm{O}_{2}$ decomposition reaction. Comparison of the present results with the literature experimental data of $n$-heptane ignition delay time shows very good agreement.

Key Words: NTC; Turnover; Auto-ignition; Chain branching ratio; Low temperature chemistry 


\section{Introduction}

The phenomenon of negative temperature coefficient (NTC) is an essential feature of the oxidation kinetics of large hydrocarbons, and is closely related to such practically important phenomena and processes as low-temperature ignition [1], cool flames [2, 3], flame stabilization [4], fuel processing [5], engine knock [6] and the development of HCCI (homogenous charge compression ignition) engines [7]. It refers to the effect that, for a given pressure and in an initial temperature regime much lower than the adiabatic flame temperature of the reacting mixture, the ignition delay could increase with increasing initial temperature. The NTC behavior in auto-ignition has been extensively observed and studied in homogenous systems such as the shock tube [8], jet-stirred reactor [9], flow reactor [10] and rapid compression machine (RCM) [11].

It is widely accepted that the NTC behavior is due to the peroxy-chemistry pathways in the low-to-intermediate temperature regimes, as discussed in [12-14]. As an example, Fig. 1 shows a schematic reaction path for the oxidation of large alkanes in such regimes. Specifically, fuel consumption occurs via $\mathrm{H}$-atom abstraction from the fuel molecule to form the alkyl radical, $\mathrm{R}$. Since $\beta$ scission is slow at low temperatures, $\mathrm{O}_{2}$ addition to the $\mathrm{R}$ radical is dominant, forming the $\mathrm{RO}_{2}$ radical. Then isomerization of $\mathrm{RO}_{2}$ forms the hydroperoxy-alkyl radical $(\mathrm{QOOH})$. Further $\mathrm{O}_{2}$ addition to $\mathrm{QOOH}$ forms a transition-ring complex $\left(\mathrm{O}_{2} \mathrm{QOOH}\right)$ that isomerizes and decomposes to form ketohydroperoxide (KET) and the hydroxyl radical $(\mathrm{OH})$ (red arrows in Fig. 1). The KET then decomposes to carbonyl, aldehyde and generates another $\mathrm{OH}$ radical, leading to the key chain branching of low-temperature chemistry. However, with increasing temperature, all the oxygen addition reactions shift towards the decomposition side, and as such the extent of low- $\mathrm{T}$ chain 
branching is reduced. Meanwhile, at higher, intermediate temperatures $(800 \mathrm{~K}<\mathrm{T}<900 \mathrm{~K}, 20$ atm for $n$-heptane), dissociation of the low-temperature intermediates (e.g., $\mathrm{RO}_{2}$ and $\left.\mathrm{QOOH}\right)$ and the $\mathrm{R}$ radical through $\beta$ scission gradually becomes important and forms different products, including alkenes, $\mathrm{HO}_{2}$ and other alkyl radicals (blue arrows in Fig. 1), which further compete with the low-temperature chain branching pathway. The backward shift of the low-temperature reaction channel, together with the favored $\beta$ scission at intermediate temperatures, results in globally reduced chemical reactivity at moderate temperatures in the NTC regime.

At intermediate-to-high initial temperatures $(900 \mathrm{~K}<\mathrm{T}<1200 \mathrm{~K}, 20 \mathrm{~atm}$ for $n$-heptane), the major chain branching that drives the system runaway is hydrogen peroxide $\left(\mathrm{H}_{2} \mathrm{O}_{2}\right)$ decomposition [15] forming two $\mathrm{OH}$ radicals, with its rate constant increasing with temperature. Consequently, the ignition delay starts to decrease again with increasing temperature beyond a threshold value, termed the "turnover temperature", corresponding to the local maximum of the ignition delay time.

In this work, the characteristics of the turnover states including the thermodynamic and chemical kinetic behaviors are studied. The motivations are three-fold: First, since the turnover state also corresponds to the intermediate-to-high temperature boundary of the NTC regime, identification of the mechanism controlling it will lead to new insights on the NTC behavior, and can bring about significant convenience in the description of auto-ignition. Second, sensitivity of the ignition delay to temperature variation is one of the key factors affecting the flame propagation mode in HCCI engines [16] and relevant RCM experiments $[17,18]$, deeper understanding of the underlying mechanism of the temperature-insensitive 
nature of the ignition delay at the turnover state could be helpful in interpreting the various combustion modes under HCCI conditions. Third, correlations of the ignition delay time as a function of initial pressure and temperature usually show large deviations near the turnover temperature $[8,19]$. Thus, developing global scaling for the turnover temperature can help to reduce the uncertainties and provide an accurate reference for the selection of experimental data at the relevant experimental conditions.

The present study is computational. The fuels investigated are $n$-butane, $n$-heptane and iso-octane, which represent typical short and long straight-chain alkanes as well as branched alkanes. The mechanisms used are the NUIG $n$-butane mechanism [20], the LLNL $n$-heptane mechanism version 3.1 [12], and the LLNL iso-octane mechanism version 3 [21], respectively. The global behaviors of the ignition delay at turnover temperatures under different pressures are investigated for all of the three fuels. It is noted that although the pressure dependence of the rate constants of the oxygen addition reactions, alkylperoxy radical $\left(\mathrm{RO}_{2}\right)$ dissociation and isomerization reactions, are not considered, it has been recently demonstrated in $[22,23]$ that the high-pressure limits for these reactions are sufficient to describe the low-temperature chemistry at the conditions of this study. The mechanism for $n$-heptane updated by Karwat et al. [24], based on the rate rules from Villano et al. [22, 23], is also referred to show that the behavior demonstrated in this study is mechanism independent and with general implications on the low-temperature kinetics.

In the following sections, we shall first identify the global system behavior at the turnover states under different pressures. We shall then analyze the coupling between pressure and the turnover temperature, as well as the power-law dependence on the pressure 
for the ignition delay at the turnover states. Finally, the characteristics of the turnover states are validated against available ignition delay data in the literature, demonstrating good agreement.

\section{Global behavior of the turnover states}

Figure 2 shows the ignition delay as a function of temperature for a homogeneous, stoichiometric mixture of $n$-heptane and air under 2-60 atm pressure, using detailed mechanism [12]. It is seen that for each pressure, the total ignition delay, $\tau$, first decreases and then increases with increasing initial temperature, $T$, in the NTC regime, and finally decreases again when the temperature is above the turnover temperature, $T_{m}$, which, marked by symbols, is seen to shift to higher values as pressure is increased.

We next note that the ignition delay, $\tau_{m}$, at the turnover state exhibits unique dependences on the corresponding temperature, $T_{m}$, and the system pressure, $P$. Specifically, its linear variation with $T_{m}$ in the plot of Fig. 2 suggests an Arrhenius correlation, namely $\ln \tau_{m} \propto 1 / T_{m}$, while Fig. 3 shows it also varies nearly quadratically with the system pressure, as $\tau_{m} \propto P^{-2}$. These results then suggest that $T_{m}$ and $P$ can be related by $\ln P \propto 1 / T_{m}$, as shown in Fig. 4, yielding a thermodynamic correlation between the turnover temperature and the system pressure. It is further noted that the data in Figs. 3 and 4 include those for $\varphi=0.5,1$ and 2, demonstrating that these observations are also insensitive to the equivalence ratio. We shall demonstrate in the following the underlying kinetic mechanism affecting such a behavior. 


\section{Chemical Kinetic Analysis on the Turnover States}

\subsection{Low-Temperature Chain Branching Ratio at the Turnover State}

Figure 5 shows the evolution of the intermediate species at the turnover states, using stoichiometric $n$-butane/air mixtures under 20 atm for demonstration because less isomers are involved in its oxidation process. It is seen that many radicals of interest, largely remain quasi-steady for an extended period between the starting chain initiation and the final ignition runaway. Take $\mathrm{OH}$ as an example, the $\mathrm{OH}$ consumption rate is about $10^{-5} \sim 10^{-4} \mathrm{~mole} / \mathrm{cm}^{3} \mathrm{~s}$ as shown in Fig. 6, while the net $\mathrm{OH}$ production rate at the same condition is below $10^{-9}$ mole $/ \mathrm{cm}^{3} \mathrm{~s}$, four orders of magnitude lower. As such, the $\mathrm{OH}$ mole fraction is kept at a low level (less than $10^{-8}$ ) before ignition as shown in Fig. 5 and could be assumed to be in quasi-steady in the plateau period. Therefore, the total production and consumption rates of $\mathrm{OH}$ should approximately balance. Figure 6 then plots the rates of the important reactions consuming $\mathrm{OH}$ and the fuel molecule, showing that $\mathrm{OH}$ is mainly consumed by $\mathrm{H}$-abstraction from the fuel molecule (nearly $90 \%$ of $\mathrm{OH}$ consumption at the instant of $75 \% \tau_{\mathrm{m}}$ in Fig. $6 \mathrm{a}$ ), while fuel consumption is also mainly through the $\mathrm{H}$-abstraction by $\mathrm{OH}$ (nearly $90 \%$ of fuel consumption at the instant of $75 \% \tau_{\mathrm{m}}$ by the four reactions in Fig. $\left.6 \mathrm{~b}\right)$. Consequently, the $\mathrm{OH}$ production rate can be estimated by the consumption rate of the fuel molecule. We shall demonstrate in the following how these observations identify the major kinetic characteristics at the turnover states.

The controlling reactions for the turnover temperature were identified by performing sensitivity analysis, with the sensitivity coefficient calculated by perturbing the A-factor of each elemental reaction rate by $30 \%$, following the definition: 


$$
S=\frac{d \ln (T)}{d \ln (k)}=\frac{\ln \left(T_{1.3 k}\right)-\ln \left(T_{k}\right)}{\ln (1.3 k)-\ln (k)}
$$

A step size of $0.1 \mathrm{~K}$ was used to search the turnover temperature, and the perturbation of $30 \%$ was selected to allow sufficient change of the turnover temperature for accurate evaluation. We shall only present the sensitivity for $n$-butane as the mechanisms for $n$-heptane and iso-octane are based on similar reaction classes and rate rules.

Figure 7 shows the sensitivity for the stoichiometric $n$-butane/air mixture at 2 and $10 \mathrm{~atm}$. The most sensitive reactions are shown to be the chain termination reactions from the $\beta$ scission of $\mathrm{RO}_{2}$ and $\mathrm{QOOH}$, as well as the isomerization from $\mathrm{RO}_{2}$ to $\mathrm{QOOH}$ and the subsequent chain branching and propagation reactions. However, it is seen that the turnover temperature is not sensitive to the $\mathrm{HO}_{2}$ chain termination reaction and the $\mathrm{H}_{2} \mathrm{O}_{2}$ chain branching reaction. Consequently, the turnover state is mainly controlled by the competition between the $\beta$ scission of low-temperature intermediates as chain termination reactions producing the stable intermediates and $\mathrm{HO}_{2}$, and the low-temperature chain branching/propagation reactions producing $\mathrm{OH}$. It should be noted that the turnover temperature is insensitive to the perturbation of the rate of oxygen addition to QOOH reaction as long as its equilibrium constant is not perturbed. Such a behavior is expected as the oxygen addition to $\mathrm{QOOH}$ is in the partial equilibrium state, and the low-T chain branching is only affected by the equilibrium constant. Therefore, the result by perturbing the oxygen addition to QOOH using reversible reactions is not presented in Fig. 7, which otherwise might cause misleading and underestimate its role at the turnover states.

We note in passing the worthwhile studies on such competitions in the first-stage ignition controlled by the low-temperature chemistry. Specifically, Peters et al. [25] defined a ratio 
between the $\mathrm{R}+\mathrm{O}_{2} \rightleftharpoons \mathrm{RO}_{2}$ with subsequent isomerization $\mathrm{RO}_{2} \rightleftharpoons \mathrm{QOOH}$ and the $\beta$ scission of $\mathrm{R}$ to determine the crossover temperature, at which the concentration of KET reaches its peak value and the first-stage ignition occurs. Merchant et al. [26] used a similar concept to study the first-stage ignition of propane, and included the $\mathrm{HO}_{2}$ chemistry, namely $\mathrm{RO}_{2} \rightarrow$ Alkene $+\mathrm{HO}_{2}$, which was not included in $[25,27]$. However, these ratios were derived from a reduced mechanism, and only specific isomers of $\mathrm{R}, \mathrm{RO}_{2}$ and $\mathrm{QOOH}$ were taken into account. Thus, these definitions are applicable only for limited conditions and for certain mechanisms, in the context of two-stage ignition. However, for the concept of the turnover state of current interest, sensitivity analysis has shown that the turnover temperature is also sensitive to the decomposition of $\mathrm{QOOH}$ to produce $\mathrm{OH}$. Consequently, we shall define a ratio of the $\mathrm{OH}$ production rate, instead of the KET production rate, to the total production rate of $\mathrm{R}$, as a criterion to evaluate the net contribution from the low-temperature chain branching:

$$
\begin{aligned}
\alpha & =\frac{\mathrm{OH} \text { production rate from low- } \mathrm{T} \text { chain-branching }}{\text { total production rate of } \mathrm{R}} \\
& =\frac{\mathrm{OH} \text { production rate from low- } \mathrm{T} \text { chain-branching }}{\text { total rate of } \mathrm{H} \text {-abstraction from } \mathrm{RH}}
\end{aligned}
$$

The ratio $\alpha$ can be readily determined from the detailed mechanism including all isomers of $\mathrm{R}$, $\mathrm{RO}_{2}$, and $\mathrm{QOOH}$. In particular, we have followed the reaction flux from $\mathrm{RH}$ to $\mathrm{OH}$, as shown in Fig. 8, and have considered the effect from $\beta$ scission at each step, defined by the following ratios:

$$
\begin{aligned}
& \eta_{i}=\frac{\text { rate of } \mathrm{RH} \rightarrow i-\mathrm{R}}{\text { total rates of } \mathrm{RH} \rightarrow \mathrm{R}} \approx \frac{\text { rate of } \mathrm{RH}+\mathrm{OH} \rightarrow i-\mathrm{R}+\mathrm{H}_{2} \mathrm{O}}{\text { total rates of } \mathrm{RH}+\mathrm{OH} \rightarrow \mathrm{R}+\mathrm{H}_{2} \mathrm{O}} \\
& \beta_{i}=\frac{\text { net rate of } i-\mathrm{R} \rightarrow i-\mathrm{RO}_{2}}{\text { total production rate of } i-\mathrm{R}}
\end{aligned}
$$


The subscript or prefix $i$ indicates the index of the isomer of $\mathrm{R}$, and those of $i, j$ indicate the index of the isomer of $\mathrm{QOOH}$. Thus, $\alpha$ is determined by

$$
\alpha=\sum_{i} \eta_{i} \beta_{i} \sum_{j} \gamma_{i, j} \theta_{i, j}
$$

In the Appendix, we present a systematic determination of $\alpha$ by first deriving it using a simplified skeletal mechanism with major reaction steps involving only one isomer, shown in Fig. 1 and Table 1. We shall then extend the analytical expressions to detailed kinetics involving all of the isomers.

We shall now show that the turnover state can be defined well by a constant value of $\alpha$ under different pressures. Following the definition of Eq. (2), the computed $\alpha$ as a function of temperature under various pressures for the three fuels are shown in Figs. 9 a, b and c, respectively. As expected, $\alpha$ decreases with increasing temperature, and eventually to zero at high enough temperatures. This shows the progressively decreasing significance of the low-temperature chain branching reactions with increasing temperature. Similar to the shift of NTC, the $\alpha$ curves shift to higher temperature with increasing pressure.

Based on $\alpha$, we define a second ratio, $\alpha_{\mathrm{RO}_{2}}$, which corresponds to the ideal case where all $\mathrm{R}$ radicals participate in the oxygen addition reaction without $\beta$ scission, i.e., $\beta_{i}=1$ :

$$
\alpha_{\mathrm{RO}_{2}}=\sum_{i} \eta_{i} \sum_{j} \gamma_{i, j} \theta_{i, j}
$$


which is also plotted in Fig. 9. Consequently, this definition isolates the effect of the competition between $\beta$ scission and oxygen addition to $\mathrm{R}$. It is seen that $\alpha_{\mathrm{RO} 2}$ is equal to $\alpha$ at low temperatures, but becomes larger than $\alpha$ when the temperature reaches a critical value at intermediate to high temperatures. These results then indicate that $\beta$ scission of the $\mathrm{R}$ radical is negligible in the low-to-intermediate temperature regime before the turnover state is reached.

In Fig. 9, the values of $\alpha$ corresponding to the turnover temperatures are marked by symbols in the evolution with increasing temperature. It is then of interest to note that the turnover temperatures for different pressures largely correspond to a narrow range of $\alpha$, which, for a given fuel, slightly depends on the pressure range. Figure 10 further shows that the turnover states calculated using a constant $\alpha$ agree well with those obtained with detailed mechanism, thereby supporting the suggestion that the turnover states can be correlated with a critical state of the low-temperature chain branching ratio, with the associated reactions involved in the determination of $\alpha$. The critical value of $\alpha$ is found to be less than one, and is different for each fuel studied here, potentially depending on the fuel structure and the range of the turnover temperatures. The pressure effect on $\alpha$ is mainly through the equilibrium shift of oxygen addition reactions, as implied from Eq. (A11) in the Appendix.

It is worth noting that the $\alpha$ ratio developed in the current work is based on the widely used rate rules in low temperature chemistry, and it can be readily extended to future mechanisms with more accurate rate coefficients. Recently, extensive work has been done on the uncertainty quantification in kinetic analysis and combustion modeling [28-30]. Following the idea of uncertainty propagation, the value of $\alpha$ in this study is rate dependent and will be affected by the uncertainty in the rate coefficients, however, such uncertainty will not affect the 
scaling characteristics and the controlling mechanism identified for the turnover states. On the other hand, there are some other factors that could affect the quantitative determination of the $\alpha$ value, such as the transient effects of species concentration and other possible reaction channels, however, those effects are secondary with negligible influence compared with the leading order quasi-steady assumptions and dominant reaction channels. It is found that the correlation of the turnover state with a constant $\alpha$ value is valid and general for different fuels and mechanisms, as demonstrated by both detailed calculations and experimental validations in Sec. 4.

\subsection{Pressure Scaling of Ignition Delay at Turnover States}

With the thermodynamic condition identified at the turnover state, we next investigate the reactions controlling the pressure-scaling factor for the turnover ignition delay, shown in Fig. 3. The sensitivity on the turnover ignition delay, defined as $S=d(\ln \tau) / d(\ln k)$ and shown in Fig. 11 for $n$-butane and $n$-heptane (results for iso-octane are similar), demonstrates that the most sensitive reactions are those involving the $\mathrm{HO}_{2}$ and $\mathrm{H}_{2} \mathrm{O}_{2}$ chemistry, while the secondary important reactions are those involved in the low-T chemistry that determine $\alpha$.

Peters et al. [25] have derived an analytical solution for the ignition delay time $\tau$ in the intermediate temperature range based on the quasi-steady-state approximation for $\mathrm{HO}_{2}$, as

$$
\tau=\xi\left(\frac{(1-\alpha)^{3} k_{11}}{2 c_{\text {Fuel }}\left(\sum_{i} k_{12, i}\right)^{2} k_{13}^{2}}\right)^{1 / 3}
$$

where $\xi$ is a proportional constant, $\alpha$ is defined by Eq. (2), $c_{\text {Fuel }}$ is the fuel concentration, and $k_{11}, k_{12, i}, k_{13}$ correspond to the rate constants of $2 \mathrm{HO}_{2} \rightarrow \mathrm{H}_{2} \mathrm{O}_{2}+\mathrm{O}_{2}(\mathrm{R} 11), \mathrm{RH}+\mathrm{HO}_{2} \rightarrow$ $i-\mathrm{R}+\mathrm{H}_{2} \mathrm{O}_{2}(\mathrm{R} 12)$, and $\mathrm{H}_{2} \mathrm{O}_{2}(+\mathrm{M}) \rightarrow 2 \mathrm{OH}(+\mathrm{M})(\mathrm{R} 13)$, respectively. Figure 12 shows the 
turnover ignition delay calculated using both detail mechanism and the correlation of Eq. (4). It is seen that very good agreement is achieved between the two, and the pressure-scaling factor for all of three fuels are well reproduced.

Equation (4) employs the rates of three types of elemental reactions, namely R11, R12, and R13 to correlate the $\mathrm{HO}_{2}$ and $\mathrm{H}_{2} \mathrm{O}_{2}$ chemistry on the ignition delay. The ratio $\alpha$ is also employed in Eq. (4) to account for the contribution from low-temperature chemistry on the ignition delay. Since $\xi$ and $\alpha$ are both constants, the change of $\tau_{m}$ is therefore dominated by the rate change of $\mathrm{R} 11, \mathrm{R} 12$, and $\mathrm{R} 13$. Especially, the $k_{13}$ corresponding to the decomposition of $\mathrm{H}_{2} \mathrm{O}_{2}$ with inherent pressure dependence is described by a Troe formula [28] and varies nearly quadratically with changes of the turnover temperature and pressure in the fall-off regime, shown in Fig. 13 . Therefore, given the fact that $\tau_{m}$ and $k_{13}$ vary nearly quadratically in terms of pressure with power index being about -2 and 2 respectively, it could be shown from Eq. (4) that the rate change of $\mathrm{H}_{2} \mathrm{O}_{2}$ decomposition reaction $\mathrm{R} 13$ contributes to about two-thirds of the pressure dependence for $\tau_{m}$, while the rate changes of R12 by the $c_{F u e l}$, i.e. $c_{\text {Fuel }} \sim P$, and the effect of temperature variation on $k_{11}, k_{12, i}$ contribute to the rest one-third.

\section{Experimental validation}

We now assess the validity of the above two global behaviors and correlations against the ignition delay data available in literature, with the ignition delay for $n$-heptane/air mixture with $\varphi=1$, covering the turnover temperature under $4-55$ atm, reported in shock tube $[8,31$, 32] and in RCM [11]. 
Gauthier et al. [8] reported a pressure scaling factor of -1.64 for the ignition delay under the pressure range of 13-55 atm by using a quadratic fitting to determine the conditions at the turnover state, while the high temperature ignition data show a scaling factor of -0.55 [33]. However, simulation using the LLNL $n$-heptane mechanism [12] shows that the ignition delay at the turnover state acquired from quadratic fitting covering the data points in regimes of both high temperature and near the turnover states is lower than the actual value. Thus, a cubic fitting covering only the points near the turnover temperature is adopted here, as shown in Fig. 14, because computation shows that the cubic relation also cannot hold far from the turnover state. Higher order fitting is also precluded due to the limited number of data points of each dataset.

The conditions corresponding to the turnover states derived from the fitting curve are plotted in Figs. 15 and 16. Strong Arrhenius dependence is found between pressure and temperature. The predictions using the LLNL $n$-heptane mechanism [12] and the updated n-heptane mechanism from Karwat et al. [24] are also plotted in Fig. 15 for comparison. Both mechanisms reproduce the Arrhenius behavior between the turnover temperature and pressure, and the "slopes" predicted from both mechanisms are close to those from the experimental data. The prediction using $\alpha=0.64$ from the LLNL $n$-heptane mechanism [12] is plotted in Fig. 14, and agrees with the experimental data very well. Strong power law dependence is also found between ignition delay and pressure with $\tau_{m} \propto P^{-1.79}$, and the correlation using Eq. (4) agrees well with the measurements in Fig. 16.

It is nevertheless also noted that the fitted turnover temperature under 12 atm from Shen et al. [31] and under $20 \mathrm{~atm}$ from Gauthier et al. [8] show large deviations from the Arrhenius 
correlation with pressure, due to the lack of data near the turnover state. The deviation is smaller for the power law between the ignition delay and pressure, as the ignition delay is not sensitive to temperature near the turnover state.

The validation demonstrates the potential to use these two behaviors and correlations to check the consistence among different ignition delay data. The correlations for the two behaviors can also be used for interpolating measured sample data to other conditions.

\section{Conclusions}

The current work investigated the thermodynamic and chemical kinetic behavior of the upper turnover states of the NTC regime, namely, the Arrhenius behavior between the turnover temperature and pressure, and the power law between the ignition delay and pressure at the turnover states. The underlying mechanism for these two behaviors was further derived from the detailed mechanism. It is found that the turnover states under different pressures correspond to a near-constant ratio $\alpha$ between the $\mathrm{OH}$ production from the low-temperature chemistry and the total fuel consumption, and that the pressure-scaling between the ignition delay at the turnover states can be correlated well using the analytical solution from Peters et al. [25]. The analytical expression for the ignition delay only employs the rates of three types of reactions on $\mathrm{HO}_{2}$ and $\mathrm{H}_{2} \mathrm{O}_{2}$ chemistry and the ratio $\alpha$.

The two behaviors and correlations were further validated against the ignition delay data for $n$-heptane/air mixture with $\varphi=1$, covering the turnover states under $4-55$ atm; demonstrating quantitative agreement.

The correlations for the two global behaviors at turnover states provide insights into the mechanism controlling the transition from low-temperature to intermediate-to-high 
temperature regimes. The behaviors and their controlling mechanism can also assist in the design and validation of measured ignition delay data near turnover states, provide reference points for developing correlation of ignition delay from experimental data, and help to identify the regime where the ignition delay is not sensitive to temperature. Furthermore, these correlations can provide targets for optimizing the reaction rate rules for the NTC chemistry.

\section{Acknowledgements}

This work was primarily supported by the National Natural Science Foundation of China 91441202. The work at Princeton University was supported by the Combustion Energy Frontier Research Center, an Energy Frontier Research Center funded by the US Department of Energy, Office of Basic Energy Sciences under Award Number DESC0001198. Peng Zhao was also supported by the startup funding at Oakland University. The guidance on the NUIG $n$-butane mechanism from Dr. Kuiwen Zhang from NUIG is very much appreciated.

\section{References}

1. C. K. Law; P. Zhao, NTC-affected ignition in nonpremixed counterflow, Combust. Flame 159 (2012) 1044-1054.

2. S. Deng; P. Zhao; D. Zhu; C. K. Law, NTC-affected ignition and low-temperature flames in nonpremixed DME/air counterflow, Combust. Flame 161 (2014) 1993-1997.

3. P. Zhao; W. Liang; S. Deng; C.K. Law, Initiation and propagation of laminar premixed cool flames, Fuel (2015) http://dx.doi.org/10.1016/j.fuel.2015.11.025.

4. S. Deng; P. Zhao; M. E. Mueller; C. K. Law, Autoignition-affected stabilization of laminar nonpremixed DME/air coflow flames, Combust. Flame 162 (2015) 3437-3445.

5. A. Naidja; C. R. Krishna; T. Butcher; D. Mahajan, Cool flame partial oxidation and its role in combustion and reforming of fuels for fuel cell systems, Prog. Energy Combust. Sci. 29 (2003) 155-191.

6. J. F. Griffiths; J. P. MacNamara; C. G. W. Sheppard; D. A. Turton; B. J. Whitaker, The 
relationship of knock during controlled autoignition to temperature inhomogeneities and fuel reactivity, Fuel 81 (2002) 2219-2225.

7. M. Yao; Z. Zheng; H. Liu, Progress and recent trends in homogeneous charge compression ignition (HCCI) engines, Prog. Energy Combust. Sci. 35 (2009) 398-437.

8. B. M. Gauthier; D. F. Davidson; R. K. Hanson, Shock tube determination of ignition delay times in full-blend and surrogate fuel mixtures, Combust. Flame 139 (2004) 300-311.

9. P. Dagaut; M. Reuillon; M. Cathonnet, High pressure oxidation of liquid fuels from low to high temperature. 1. n-Heptane and iso-Octane, Combust. Sci. Tecnol. 95 (1993) 233-260. 10. T. Wada; A. Sudholt; H. Pitsch; N. Peters, Analysis of first stage ignition delay times of dimethyl ether in a laminar flow reactor, Combustion Theory and Modelling 17 (2013) 906-936.

11. R. Minetti; M. Carlier; M. Ribaucour; E. Therssen; L. R. Sochet, A rapid compression machine investigation of oxidation and auto-ignition of n-Heptane: Measurements and modeling, Combust. Flame 102 (1995) 298-309.

12. M. Mehl; W. J. Pitz; C. K. Westbrook; H. J. Curran, Kinetic modeling of gasoline surrogate components and mixtures under engine conditions, Proc. Combust. Inst. 33 (2011) 193-200.

13. J. A. Miller; M. J. Pilling; J. Troe, Unravelling combustion mechanisms through a quantitative understanding of elementary reactions, Proc. Combust. Inst. 30 (2005) 43-88.

14. H. J. Curran; P. Gaffuri; W. J. Pitz; C. K. Westbrook, A Comprehensive Modeling Study of n-Heptane Oxidation, Combust. Flame 114 (1998) 149-177.

15. C. K. Westbrook, Chemical kinetics of hydrocarbon ignition in practical combustion systems, Proc. Combust. Inst. 28 (2000) 1563-1577.

16. J. H. Chen; E. R. Hawkes; R. Sankaran; S. D. Mason; H. G. Im, Direct numerical simulation of ignition front propagation in a constant volume with temperature inhomogeneities: I. Fundamental analysis and diagnostics, Combust. Flame 145 (2006) 128-144.

17. H. G. Im; P. Pal; M. S. Wooldridge; A. B. Mansfield, A Regime Diagram for Autoignition of Homogeneous Reactant Mixtures with Turbulent Velocity and Temperature Fluctuations, Combust. Sci. Tecnol. 187 (2015) 1263-1275.

18. K. P. Grogan; S. Scott Goldsborough; M. Ihme, Ignition regimes in rapid compression machines, Combust. Flame 162 (2015) 3071-3080.

19. S. S. Goldsborough, A chemical kinetically based ignition delay correlation for iso-octane covering a wide range of conditions including the NTC region, Combust. Flame 156 (2009) 1248-1262.

20. D. Healy; N. S. Donato; C. J. Aul; E. L. Petersen; C. M. Zinner; G. Bourque; H. J. Curran, n-Butane: Ignition delay measurements at high pressure and detailed chemical kinetic simulations, Combust. Flame 157 (2010) 1526-1539.

21. M. Mehl; H. Curran; W. Pitz; C. Westbrook, Chemical kinetic modeling of component mixtures relevant to gasoline, European Combustion Meeting (2009)

22. S. M. Villano; L. K. Huynh; H.-H. Carstensen; A. M. Dean, High-Pressure Rate Rules for Alkyl $+\mathrm{O} 2$ Reactions. 2. The Isomerization, Cyclic Ether Formation, and $\beta$-Scission Reactions of Hydroperoxy Alkyl Radicals, J. Phys. Chem. A 116 (2012) 5068-5089.

23. S. M. Villano; L. K. Huynh; H.-H. Carstensen; A. M. Dean, High-Pressure Rate Rules for 
Alkyl + O2 Reactions. 1. The Dissociation, Concerted Elimination, and Isomerization Channels of the Alkyl Peroxy Radical, J. Phys. Chem. A 115 (2011) 13425-13442.

24. D. M. A. Karwat; S. W. Wagnon; M. S. Wooldridge; C. K. Westbrook, Low-temperature speciation and chemical kinetic studies of n-heptane, Combust. Flame 160 (2013) 2693-2706. 25. N. Peters; G. Paczko; R. Seiser; K. Seshadri, Temperature cross-over and non-thermal runaway at two-stage ignition of n-heptane, Combust. Flame 128 (2002) 38-59.

26. S. S. Merchant; C. F. Goldsmith; A. G. Vandeputte; M. P. Burke; S. J. Klippenstein; W. H. Green, Understanding low-temperature first-stage ignition delay: Propane, Combust. Flame 162 (2015) 3658-3673.

27. J. Beeckmann; L. Cai; A. Berens; N. Peters; H. Pitsch, An analytical approximation for low- and high-temperature autoignition for dimethyl ether-air mixtures, Proc. Combust. Inst. 35 (2015) 275-281.

28. L. Cai; H. Pitsch, Optimized chemical mechanism for combustion of gasoline surrogate fuels, Combust. Flame 162 (2015) 1623-1637.

29. L. Cai; H. Pitsch, Mechanism optimization based on reaction rate rules, Combust. Flame 161 (2014) 405-415.

30. H. Wang; D. A. Sheen, Combustion kinetic model uncertainty quantification, propagation and minimization, Prog. Energy Combust. Sci. 47 (2015) 1-31.

31. H.-P. S. Shen; J. Steinberg; J. Vanderover; M. A. Oehlschlaeger, A shock tube study of the ignition of n-heptane, n-decane, n-dodecane, and n-tetradecane at elevated pressures, Energy Fuels 23 (2009) 2482-2489.

32. H. K. Ciezki; G. Adomeit, Shock-tube investigation of self-ignition of n-heptane-air mixtures under engine relevant conditions, Combust. Flame 93 (1993) 421-433.

33. D. C. Horning; D. F. Davidson; R. K. Hanson, Study of the High-Temperature Autoignition of n-Alkane/O/Ar Mixtures, Journal of Propulsion and Power 18 (2002) 363-371. 


\section{Appendix: Determination of the Low Temperature Chain Branching Ratio $\alpha$}

Species time histories plotted in Fig. 5 show that it is justified to set $\mathrm{R}, \mathrm{RO}_{2}, \mathrm{QOOH}$, $\mathrm{O}_{2} \mathrm{QOOH}$ and KET into quasi-steady state, for which the production rates balance the consumption rates, yielding:

$$
\begin{gathered}
w_{1}=w_{2}+w_{\overline{3}} \underline{w}_{93}{ }_{3} w w_{-3}=w+_{4} w_{5} \quad \underline{w} \\
w_{5}=w_{-5}+w_{6}+w_{7}+w_{8}-w_{-8} \\
w_{8}=w_{-8}+w_{9}, w_{9}=w_{10}
\end{gathered}
$$

From the definition of $\theta$ and applying Eq. (A3-A5), we have

$$
\theta=\frac{w_{7}+w_{9}+w_{10}}{w_{5}}=\frac{w_{7}+2 w_{9}}{w_{-5}+w_{6}+w_{7}+w_{9}}
$$

Introducing Eq. (A4) and the rate expressions into Eq. (A6), and further define

$$
K_{8}=k_{8} /\left(k_{-8}+k_{9}\right) \text {, we obtain }
$$

$$
\theta=\frac{k_{7}+2 k_{9} K_{8}\left[\mathrm{O}_{2}\right]}{k_{-5}+k_{6}+k_{7}+k_{9} K_{8}\left[\mathrm{O}_{2}\right]}
$$

Recall the definition of $\gamma$, and assume $w_{5}>>w_{-5}$, we obtain

$$
\gamma=\frac{w_{5}-w_{-5}}{w_{3}-w_{-3}} \approx \frac{w_{5}}{w_{4}+w_{5}}=\frac{k_{5}}{k_{4}+k_{5}}
$$

which is only temperature dependent.

Recall the definition of $\beta$ :

$$
\beta=\frac{w_{3}-w_{-3}}{w_{1}}=\frac{w_{3}-w_{-3}}{w_{2}+w_{3}-w_{-3}}
$$

Substitute Eq. (A2) into Eq. (A9) with rate expressions, and further define $K_{3}=k_{3} /\left(k_{-3}+k_{4}+k_{5}\right)$, we have $\beta$ as 


$$
\beta=\frac{\left(k_{4}+k_{5}\right) K_{3}\left[\mathrm{O}_{2}\right]}{k_{2}+\left(k_{4}+k_{5}\right) K_{3}\left[\mathrm{O}_{2}\right]}
$$

As there is only one isomer of $\mathrm{R}$ is involved, we have $\eta=1$. By substituting Eq. (A7), Eq. (A8) and Eq. (A10) into Eq. (2), we obtain

$$
\alpha=\frac{\left(k_{4}+k_{5}\right) K_{3}\left[\mathrm{O}_{2}\right]}{k_{2}+\left(k_{4}+k_{5}\right) K_{3}\left[\mathrm{O}_{2}\right]} \frac{k_{5}}{k_{4}+k_{5}} \frac{k_{7}+2 k_{9} K_{8}\left[\mathrm{O}_{2}\right]}{k_{-5}+k_{6}+k_{7}+k_{9} K_{8}\left[\mathrm{O}_{2}\right]}
$$

Clearly, it depends on both temperature and pressure, with the pressure dependence mainly through the oxygen concentration and therefore oxygen addition reactions.

To determine $\alpha$ using detailed mechanism, the reaction path and rate corresponding to each isomer should be taken into account for different low-temperature intermediates. In the following, we shall present the adaptive definitions of $\beta_{i}, \gamma_{i, j}$ and $\theta_{i, j}$ considering isomeric effects.

Merchant $e$ a al. [26] noticed that the decomposition of $\mathrm{O}_{2} \mathrm{QOOH}$ to KET and subsequent reactions may lead to three $\mathrm{OH}$ in some cases, e.g., the case where $\mathrm{CH}_{2} \mathrm{CHO}$ is in the products of KET decomposition. Besides, detailed mechanism shows that R7 and subsequent reactions may lead to more than one $\mathrm{OH}$ in some cases, e.g., the reaction of $\mathrm{C}_{7} \mathrm{H}_{14} \mathrm{OOH} 1-3 \rightarrow$ $\mathrm{C}_{4} \mathrm{H}_{7} \mathrm{OOH} 1-4+\mathrm{NC}_{3} \mathrm{H}_{7}$ will lead to two $\mathrm{OH}$ radicals in the LLNL $n$-heptane mechanism [12]. For generality, the number of $\mathrm{OH}$ produced by $\mathrm{R} 7$ and $\mathrm{R} 9$ with their subsequent reactions are denoted as $n_{7}, n_{9}$, respectively, and $\theta_{i, j}$ is determined by rewriting Eq. (A7) as

$$
\theta_{i, j}=\left\{\frac{n_{7} k_{7}^{i, j}+n_{9} k_{9}^{i, j} K_{8}^{i, j}\left[\mathrm{O}_{2}\right]}{k_{-5}^{i, j}+k_{6}^{i, j}+k_{7}^{i, j}+k_{9}^{i, j} K_{8}^{i, j}\left[\mathrm{O}_{2}\right]}\right\}_{i, j-\mathrm{QOOH}}
$$

where the superscript $i, j$ indicates that the rate constant corresponds to the specific isomer of $i, j-\mathrm{QOOH}$.

As $i-\mathrm{RO}_{2}$ can isomerize to several isomers of QOOH, $\gamma_{\mathrm{i}, \mathrm{j}}$ can be determined by including 
all of the isomerization reactions from $i-\mathrm{RO}_{2}$ and rewriting Eq. (A8) as

$$
\gamma_{i, j}=\left\{\frac{k_{5}^{i, j}}{k_{4}^{i}+\sum_{m} k_{5}^{i, m}}\right\}_{i-\mathrm{RO}_{2} \rightarrow i, j-\mathrm{QOOH}}
$$

where $k_{5}^{i, j}$ corresponds to the rate of isomerization from $i-\mathrm{RO}_{2}$ to $i, j-\mathrm{QOOH}$.

The $\beta_{i}$ can be determined by specifying the rates in Eq. (A10) for each isomer of $i$-R as.

$$
\beta_{i}=\left\{\frac{\left(k_{4}^{i}+\sum_{m} k_{5}^{i, m}\right) K_{3}^{i}\left[\mathrm{O}_{2}\right]}{k_{2}^{i}+\left(k_{4}^{i}+\sum_{m} k_{5}^{i, m}\right) K_{3}^{i}\left[\mathrm{O}_{2}\right]}\right\}_{i-\mathrm{R}}
$$

Similarly, $\eta_{i}$ is determined by

$$
\eta_{i}=\frac{w_{1}^{i}}{\sum_{m} w_{1}^{m}}=\frac{k_{1}^{i}}{\sum_{m} k_{1}^{m}}
$$




\section{List of Tables}

Table 1. Reactions used for determining $\alpha$.

\begin{tabular}{llll}
\hline Label & Reaction & Rate coefficient & Rate \\
\hline $\mathrm{R} 1$ & $\mathrm{RH}+\mathrm{OH} \rightarrow \mathrm{R}+\mathrm{H}_{2} \mathrm{O}$ & $k_{1}$ & $w_{1}$ \\
$\mathrm{R} 2$ & $\mathrm{R} \rightarrow \mathrm{R} 1+$ Alkene & $k_{2}$ & $w_{2}$ \\
$\mathrm{R} 3$ & $\mathrm{R}+\mathrm{O}_{2} \rightleftharpoons \mathrm{RO}_{2}$ & $k_{3}, k_{-3}{ }^{\mathrm{a}}$ & $w_{3}, w_{-3}{ }^{\mathrm{a}}$ \\
$\mathrm{R} 4$ & $\mathrm{RO}_{2} \rightarrow \mathrm{Alkene}+\mathrm{HO}_{2}$ & $k_{4}$ & $w_{4}$ \\
$\mathrm{R} 5$ & $\mathrm{RO}_{2} \rightleftharpoons \mathrm{QOOH}$ & $k_{5}, k_{-5}$ & $w_{5}, w_{-5}$ \\
$\mathrm{R} 6$ & $\mathrm{QOOH} \rightarrow \mathrm{Alkene}+\mathrm{HO}_{2}{ }^{\mathrm{b}}$ & $k_{6}$ & $w_{6}$ \\
$\mathrm{R} 7$ & $\mathrm{QOOH} \rightarrow \mathrm{Epoxide}+\mathrm{OH}^{\mathrm{c}}$ & $k_{7}$ & $w_{7}$ \\
$\mathrm{R} 8$ & $\mathrm{QOOH}+\mathrm{O}_{2} \rightleftharpoons \mathrm{O}_{2} \mathrm{QOOH}$ & $k_{8,}, k_{-8}$ & $w_{8,}, w_{-8}$ \\
$\mathrm{R} 9$ & $\mathrm{O}_{2} \mathrm{QOOH} \rightarrow \mathrm{KET}+\mathrm{OH}$ & $k_{9}$ & $w_{9}$ \\
$\mathrm{R} 10$ & $\mathrm{KET} \rightarrow \mathrm{P}+\mathrm{OH}$ & $k_{10}$ & $w_{10}$ \\
\hline
\end{tabular}

${ }^{a} k_{-3}$ is corresponding to the reverse rate of $k_{3}$

${ }^{\mathrm{b}}$ Decomposition reaction of QOOH that does not lead to OH production is also classified in R6

${ }^{\mathrm{c}}$ Decomposition reaction of $\mathrm{QOOH}$ that leads to one $\mathrm{OH}$ radical is also classified in $\mathrm{R} 7$ 


\section{Figure Captions}

Fig. 1. Schematic mechanism for the low temperature oxidation of a large alkane, RH.

Fig. 2. Total ignition delay as a function of the initial temperature $T$ for stoichiometric $n$-heptane/air mixture under various pressure. The turnover ignition delays are marked by the triangle symbols, showing an Arrhenius dependence on the turnover temperature for different pressures.

Fig. 3. Computed ignition delays at turnover temperatures for stoichiometric $n$-butane, $n$-heptane and iso-octane in air. The turnover ignition delays show a power law dependence on the pressure, to the order of -2, approximately.

Fig. 4. Dependence of pressure and temperature at the turnover states for stoichiometric $n$-butane, $n$-heptane and iso-octane in air.

Fig. 5. Computed species and temperature profiles for stoichiometric $n$-butane/air mixture at the turnover temperature under $20 \mathrm{~atm}$.

Fig. 6. Magnitudes of the rates of important reactions producing or consuming $\mathrm{OH}$ (a) and fuel molecule (b) for stoichiometric $n$-butane/air mixture at the turnover temperature under 20 atm.

Fig. 7. The brute force sensitivity on the turnover temperature for stoichiometric $n$-butane/air mixture.

Fig. 8. Reaction flux from $\mathrm{RH}$ to $\mathrm{OH}$ and the definition of $\eta_{i}, \beta_{i}, \gamma_{i, j}, \theta_{i, j}$. Only one of the isomers at every step is presented as an example.

Fig. 9. Computed $\alpha$ and $\alpha_{\mathrm{RO} 2}$ as a function of temperature under various pressures.

Fig. 10. Turnover temperature calculated using detailed mechanism and obtained at a constant $\alpha$. 
Fig. 11. The brute force sensitivity on the ignition delay at turnover temperature for $n$-butane and $n$-heptane.

Fig. 12. The ignition delays from simulation using detailed mechanism and from the correlation using Eq. (4).

Fig. 13. The rates of $\mathrm{H}_{2} \mathrm{O}_{2}(+\mathrm{M}) \rightarrow 2 \mathrm{OH}(+\mathrm{M})$ as a function of pressure at turnover temperature, and those rates at various temperature and pressure.

Fig. 14. Ignition delay data for stoichiometric $n$-heptane/air mixture under various pressure.

All the data are scaled to the listed pressures using $\tau \propto P^{-1}$ to account for deviations in experimental pressure [31]. Each dataset is fitted using a cubic polynomial and covering the points near turnover temperature.

Fig. 15. The pressure and turnover temperature of each dataset.

Fig. 16. The ignition delay from measurements and those from correlation using Eq. (4). 


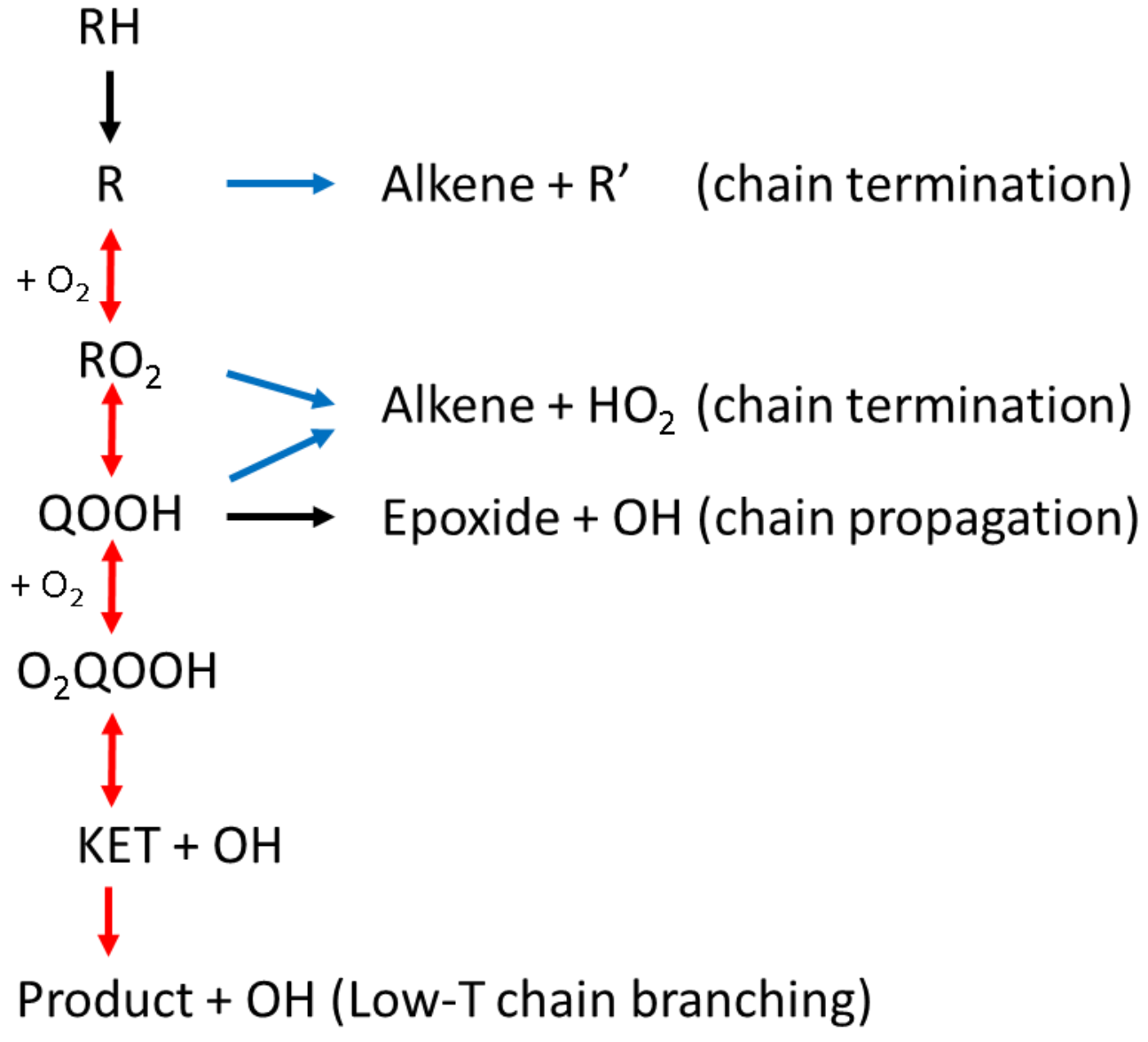

Fig. 1. Schematic mechanism for the low temperature oxidation of a large alkane, RH. 


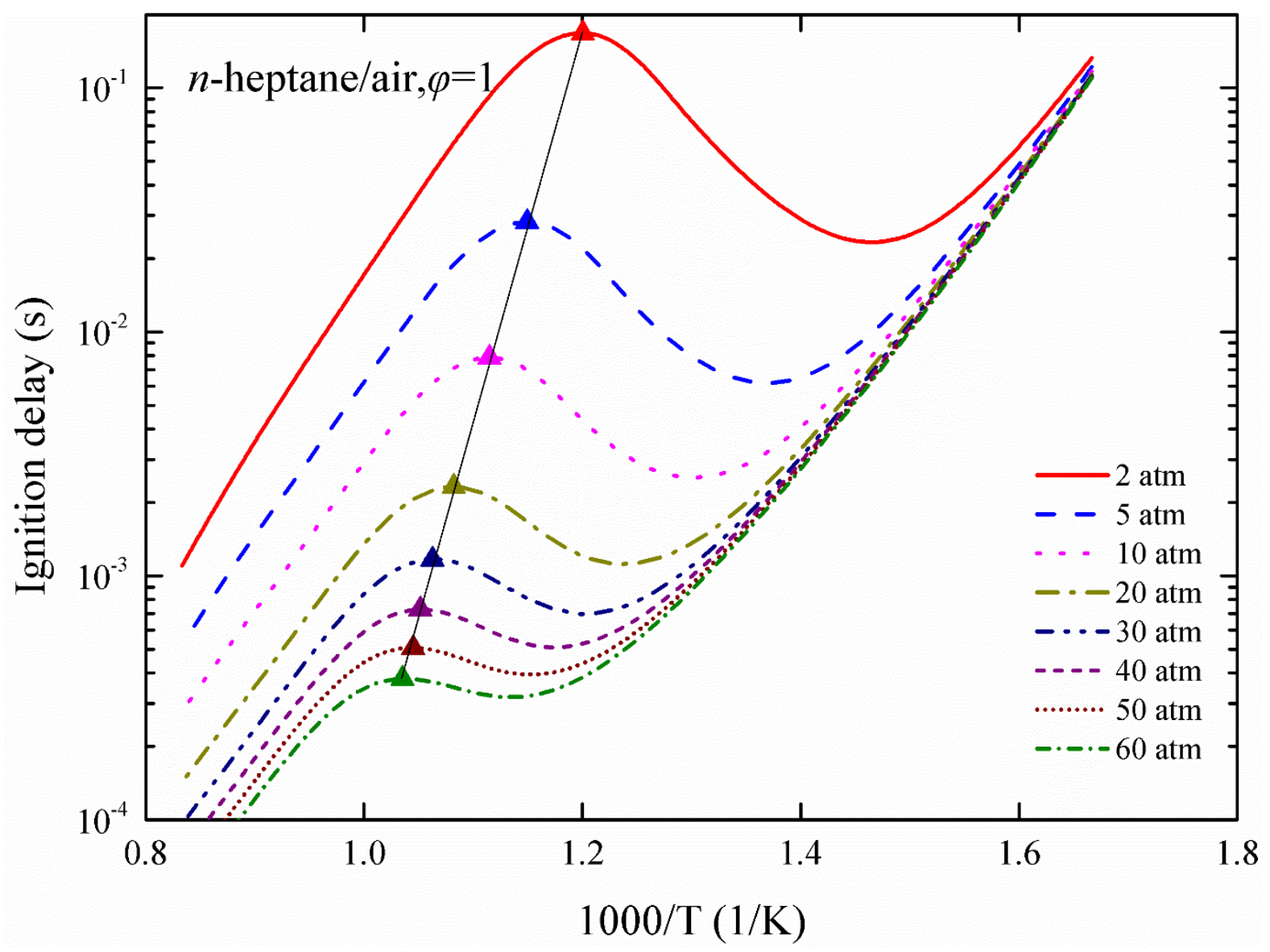

Fig. 2. Total ignition delay as a function of the initial temperature $T$ for stoichiometric $n$-heptane/air mixture under various pressure. The turnover ignition delays are marked by the triangle symbols, showing an Arrhenius dependence on the turnover temperature for different pressures. 


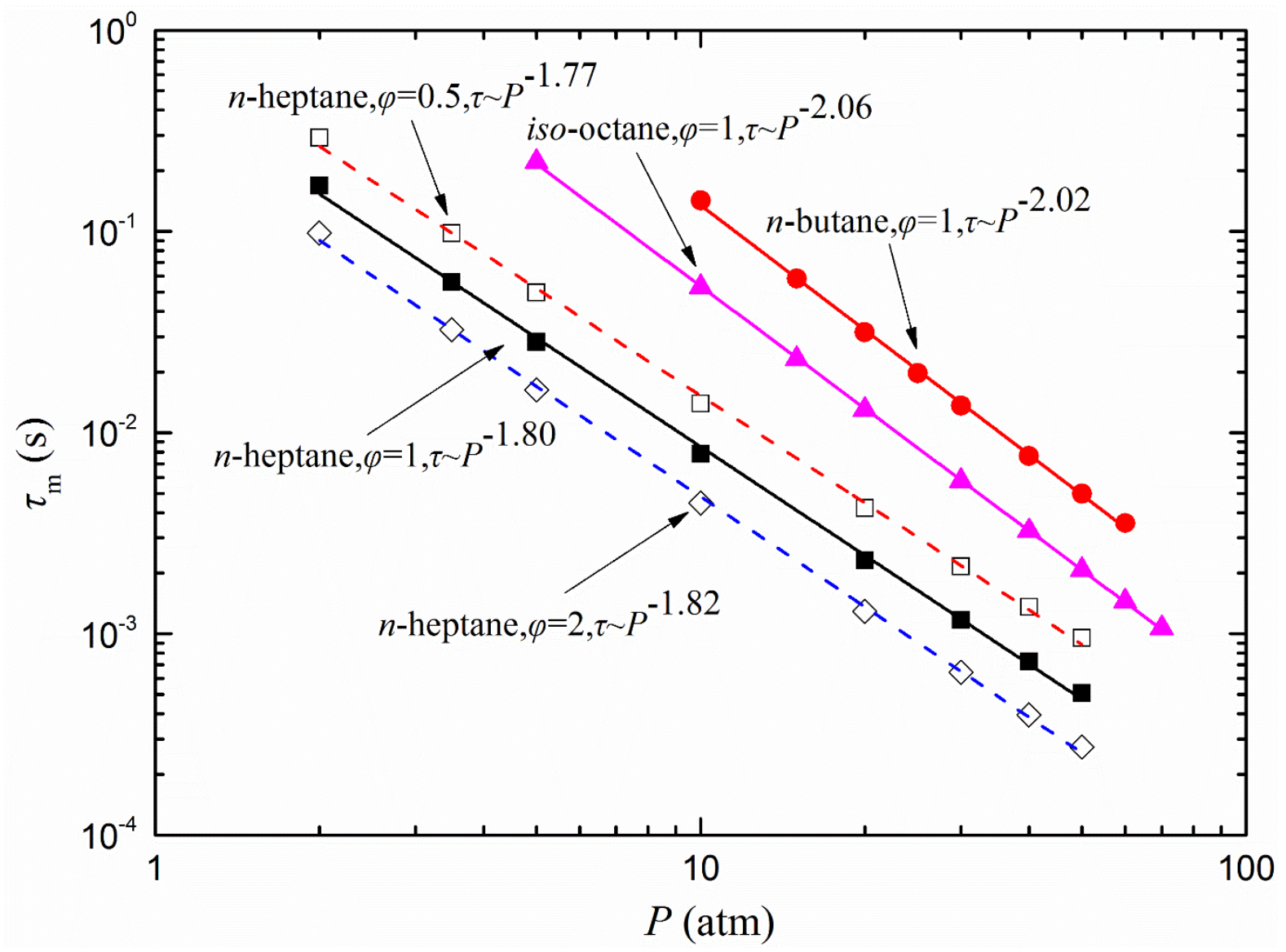

Fig. 3. Computed ignition delays at turnover temperatures for stoichiometric n-butane, $n$-heptane and iso-octane in air. The turnover ignition delays show a power law dependence on the pressure, to the order of -2 , approximately. 


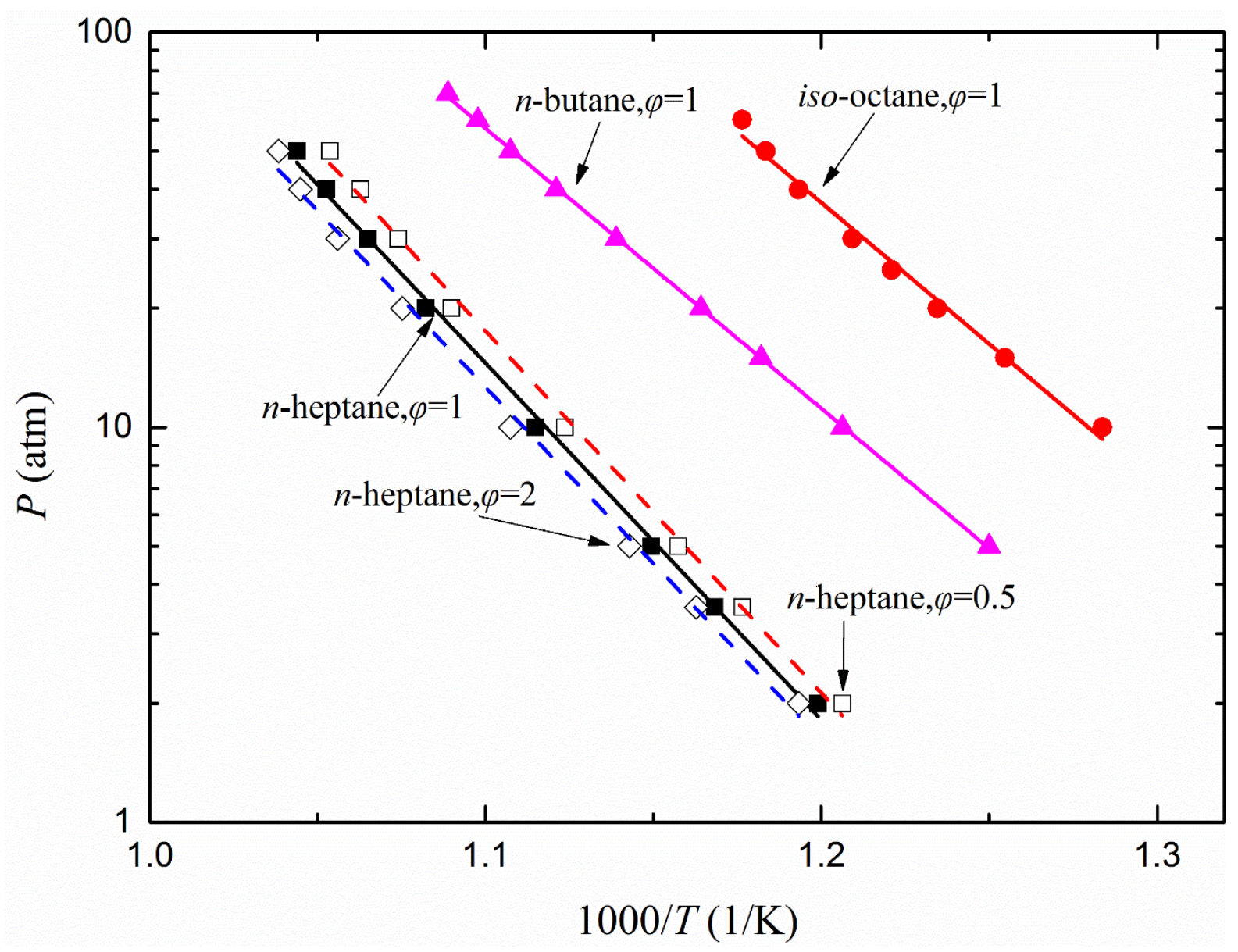

Fig. 4. Dependence of pressure and temperature at the turnover states for stoichiometric $n$-butane, $n$-heptane and iso-octane in air. 


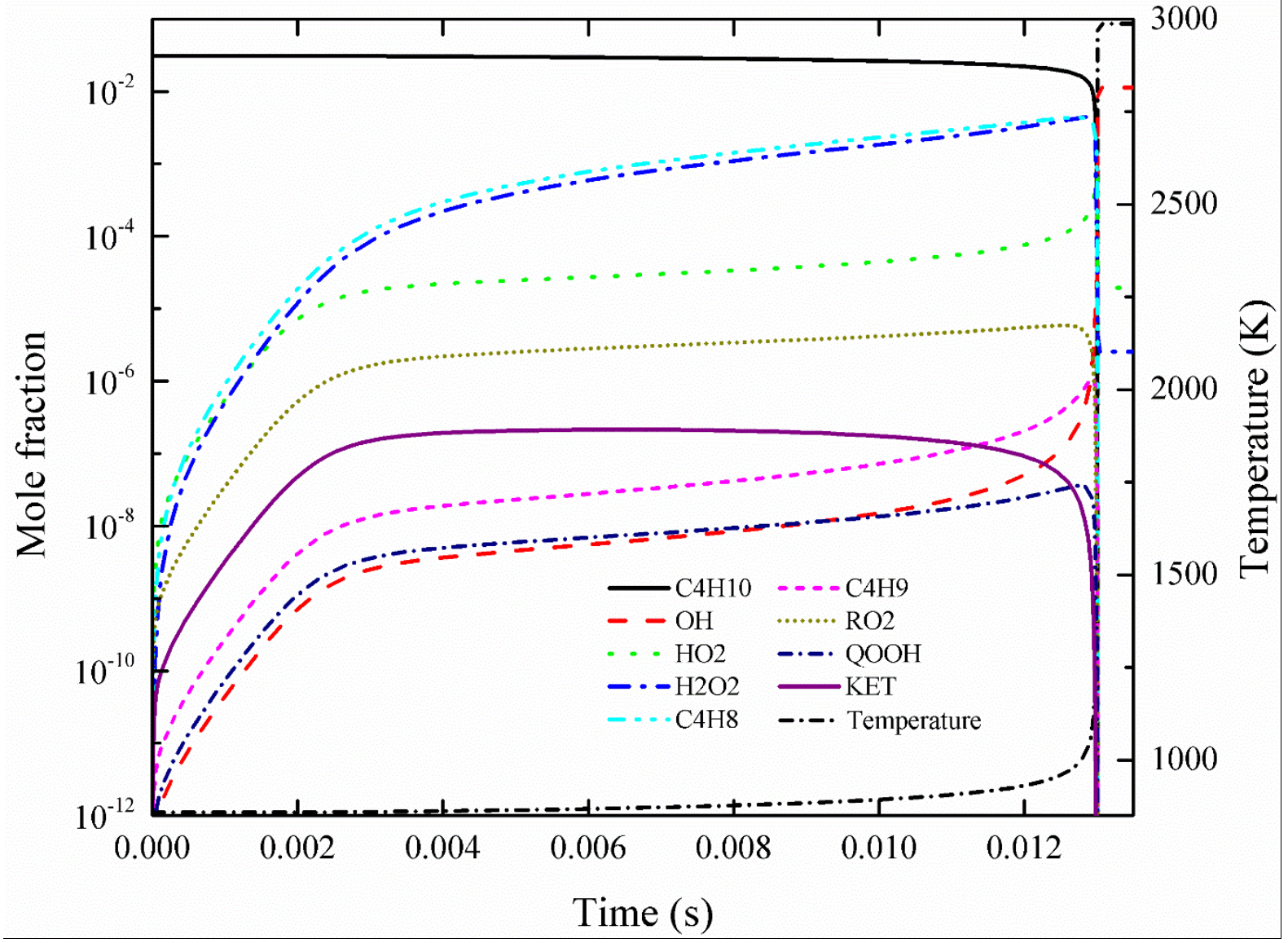

Fig. 5. Computed species and temperature profiles for stoichiometric $n$-butane/air mixture at the turnover temperature under 20 atm. 


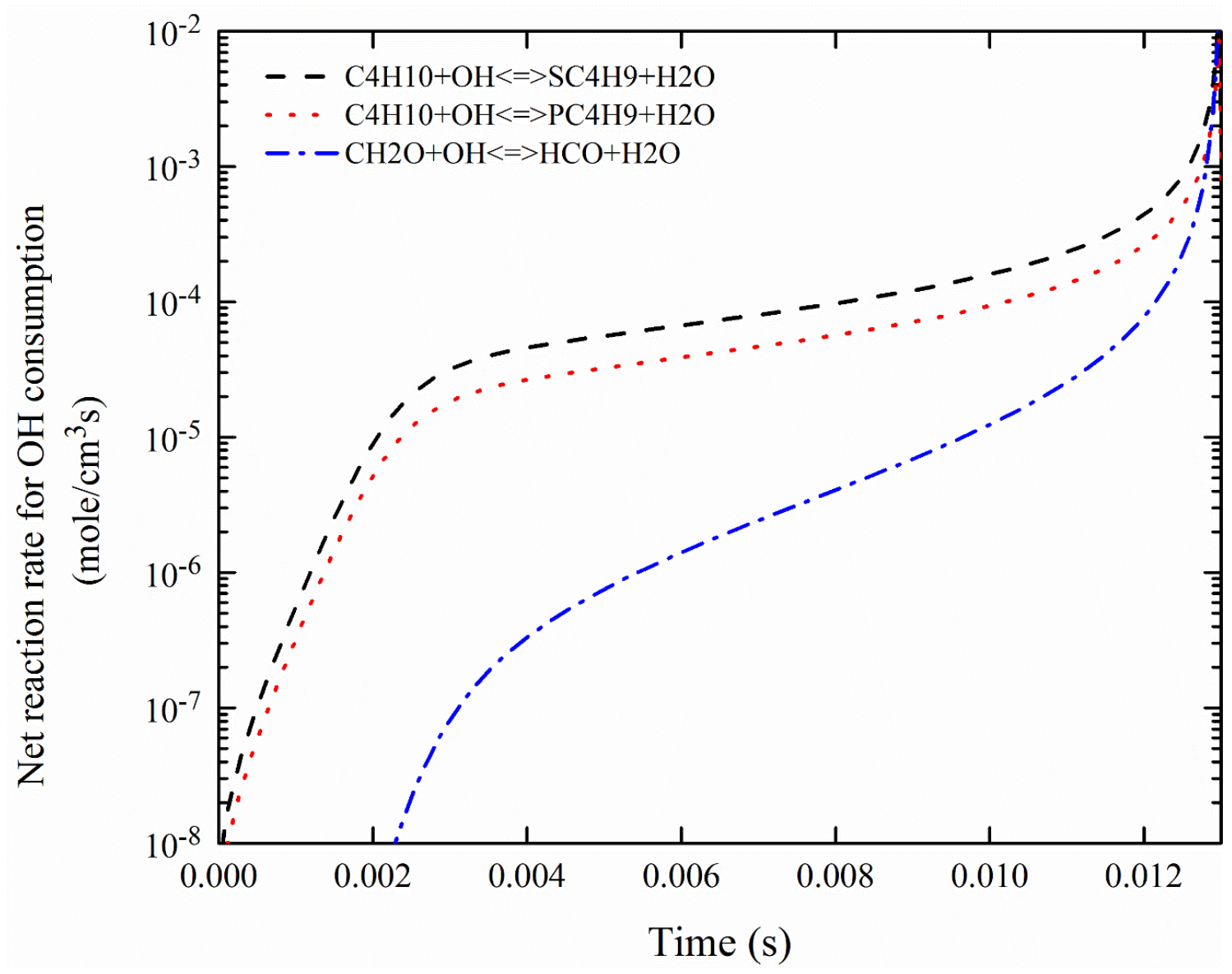

(a) 


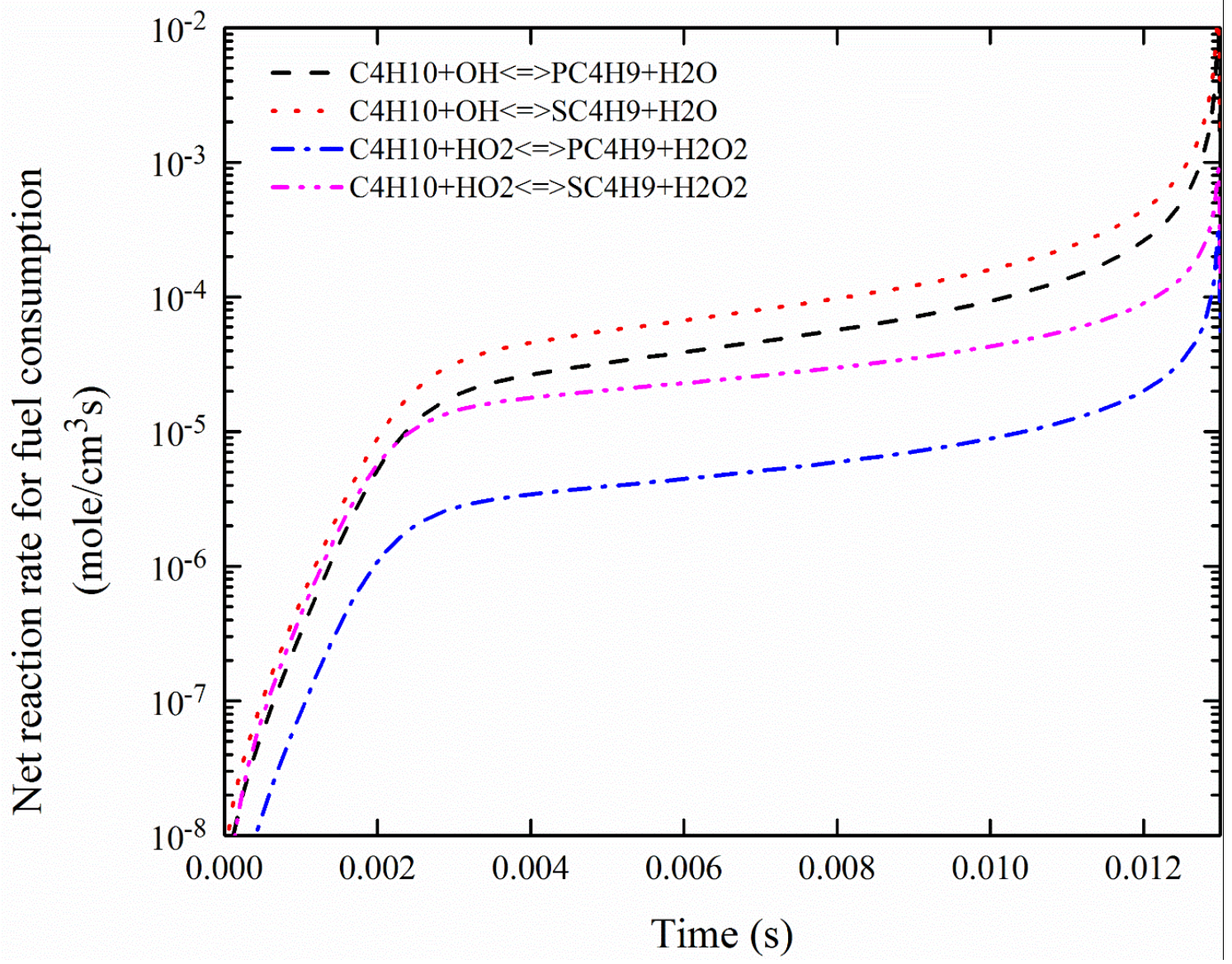

(b)

Fig. 6. Magnitudes of the rates of important reactions consuming $\mathrm{OH}$ (a) and fuel molecule (b) for stoichiometric $n$-butane/air mixture at the turnover temperature under $20 \mathrm{~atm}$. The presented reactions contribute nearly $90 \%$ to the total consumption rate at the instant of $75 \%$ 
$\mathrm{SC} 4 \mathrm{H} 9 \mathrm{O} 2 \Leftrightarrow \mathrm{C} 4 \mathrm{H} 8 \mathrm{OOH} 2-4$

$\mathrm{SC} 4 \mathrm{H} 9 \mathrm{O} 2 \Leftrightarrow \mathrm{C} 4 \mathrm{H} 8 \mathrm{OOH} 2-3$

$\mathrm{SC} 4 \mathrm{H} 9 \mathrm{O} 2<\Rightarrow \mathrm{C} 4 \mathrm{H} 8-2+\mathrm{HO} 2$

$\mathrm{SC} 4 \mathrm{H} 9 \mathrm{O} 2 \Leftrightarrow \mathrm{C} 4 \mathrm{H} 8-1+\mathrm{HO} 2$

$\mathrm{PC} 4 \mathrm{H} 9 \mathrm{O} 2 \Leftrightarrow \mathrm{C} 4 \mathrm{H} 8 \mathrm{OOH} 1-3$

$\mathrm{PC} 4 \mathrm{H} 9 \mathrm{O} 2 \Leftrightarrow \mathrm{C} 4 \mathrm{H} 8 \mathrm{OOH} 1-2$

$\mathrm{PC} 4 \mathrm{H} 9 \mathrm{O} 2<\Rightarrow \mathrm{C} 4 \mathrm{H} 8-1+\mathrm{HO} 2$

$\mathrm{HO} 2+\mathrm{HO} 2<=>\mathrm{H} 2 \mathrm{O} 2+\mathrm{O} 2$

$\mathrm{H} 2 \mathrm{O} 2(+\mathrm{M})<=>\mathrm{OH}+\mathrm{OH}(+\mathrm{M})$ $\mathrm{C} 4 \mathrm{H} 8 \mathrm{OOH} 2-4 \mathrm{O} 2=>\mathrm{C} 4 \mathrm{H} 8 \mathrm{OOH} 2-4+\mathrm{O} 2$

$\mathrm{C} 4 \mathrm{H} 8 \mathrm{OOH} 2-4 \mathrm{O} 2 \Leftrightarrow \mathrm{NC} 4 \mathrm{KET} 24+\mathrm{OH}$ $\mathrm{C} 4 \mathrm{H} 8 \mathrm{OOH} 2-4+\mathrm{O} 2=\mathrm{C} 4 \mathrm{H} 8 \mathrm{OOH} 2-4 \mathrm{O} 2$ $\mathrm{C} 4 \mathrm{H} 8 \mathrm{OOH} 2-3 \mathrm{O} 2=\mathrm{C} 4 \mathrm{H} 8 \mathrm{OOH} 2-3+\mathrm{O} 2$ $\mathrm{C} 4 \mathrm{H} 8 \mathrm{OOH} 2-3 \mathrm{O} 2<=>\mathrm{NC} 4 \mathrm{KET} 23+\mathrm{OH}$

$\mathrm{C} 4 \mathrm{H} 8 \mathrm{OOH} 2-3 \Leftrightarrow \mathrm{C} 4 \mathrm{H} 8-2+\mathrm{HO} 2$ $\mathrm{C} 4 \mathrm{H} 8 \mathrm{OOH} 2-3+\mathrm{O} 2=>\mathrm{C} 4 \mathrm{H} 8 \mathrm{OOH} 2-3 \mathrm{O} 2$ $\mathrm{C} 4 \mathrm{H} 8 \mathrm{OOH} 1-3 \mathrm{O} 2 \Rightarrow \mathrm{C} 4 \mathrm{H} 8 \mathrm{OOH} 1-3+\mathrm{O} 2$ $\mathrm{C} 4 \mathrm{H} 8 \mathrm{OOH} 1-3 \mathrm{O} 2 \Leftrightarrow \mathrm{NC} 4 \mathrm{KET} 13+\mathrm{OH}$

$\mathrm{C} 4 \mathrm{H} 8 \mathrm{OOH} 1-3 \Leftrightarrow \mathrm{C} 4 \mathrm{H} 8 \mathrm{O} 1-3+\mathrm{OH}$ $\mathrm{C} 4 \mathrm{H} 8 \mathrm{OOH} 1-3+\mathrm{O} 2=\mathrm{C} 4 \mathrm{H} 8 \mathrm{OOH} 1-3 \mathrm{O} 2$

$\mathrm{C} 4 \mathrm{H} 10+\mathrm{OH} \Leftrightarrow \mathrm{SC} 4 \mathrm{H} 9+\mathrm{H} 2 \mathrm{O}$

$\mathrm{C} 4 \mathrm{H} 10+\mathrm{OH}<=>$ PC4H9 $+\mathrm{H} 2 \mathrm{O}$

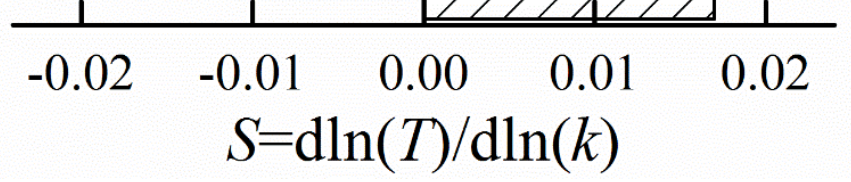

Fig. 7. The brute force sensitivity on the turnover temperature for stoichiometric $n$-butane/air mixture. 


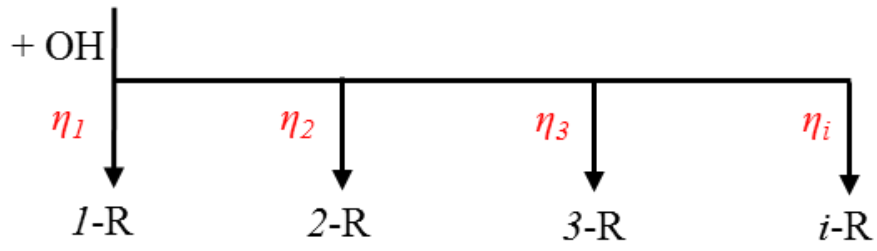

Fig. 8. Reaction flux from $\mathrm{RH}$ to $\mathrm{OH}$ and the definition of $\eta_{i}, \beta_{i}, \gamma_{i, j}, \theta_{i, j}$. Only one of the isomers at every step is presented as an example. 


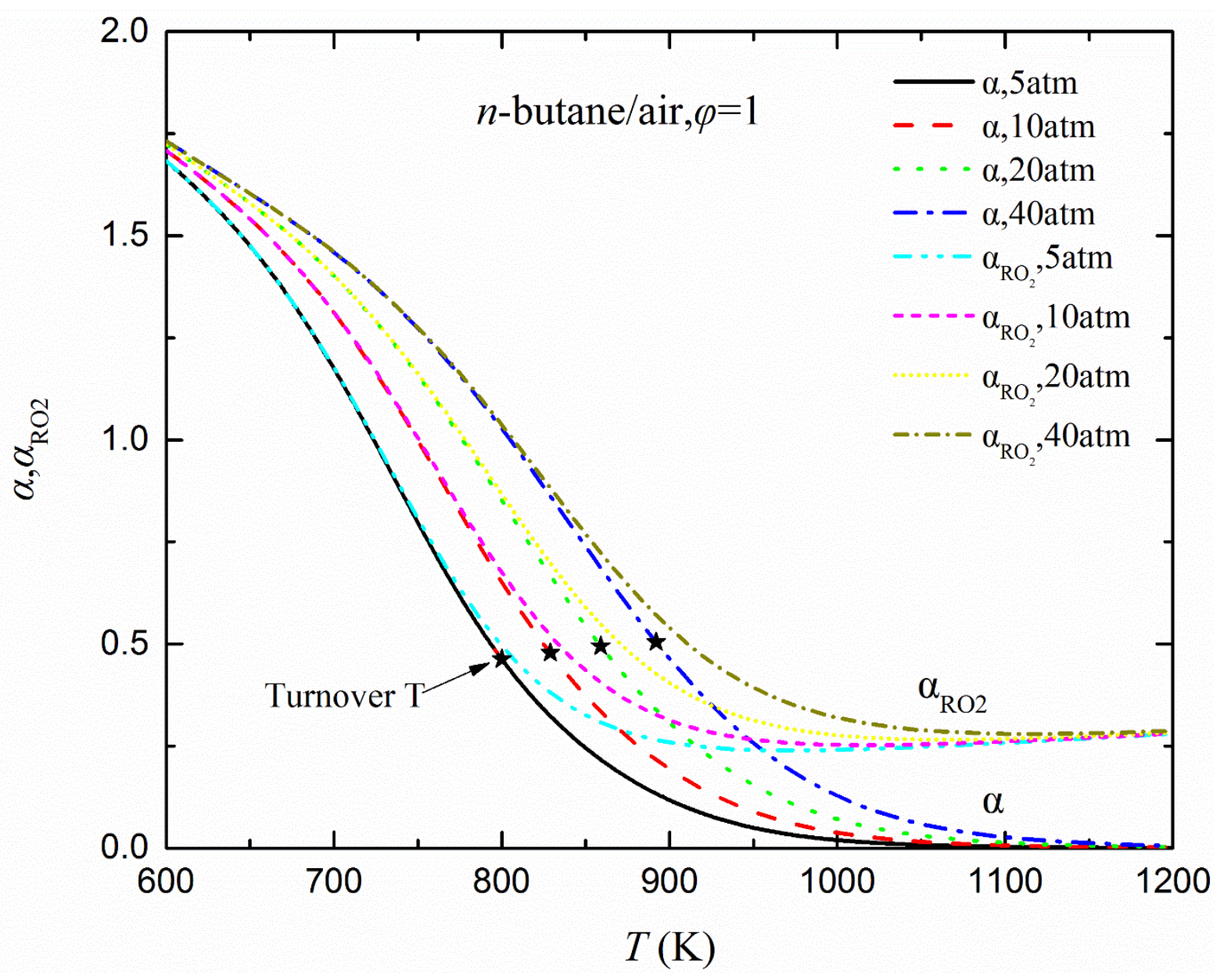

(a) 


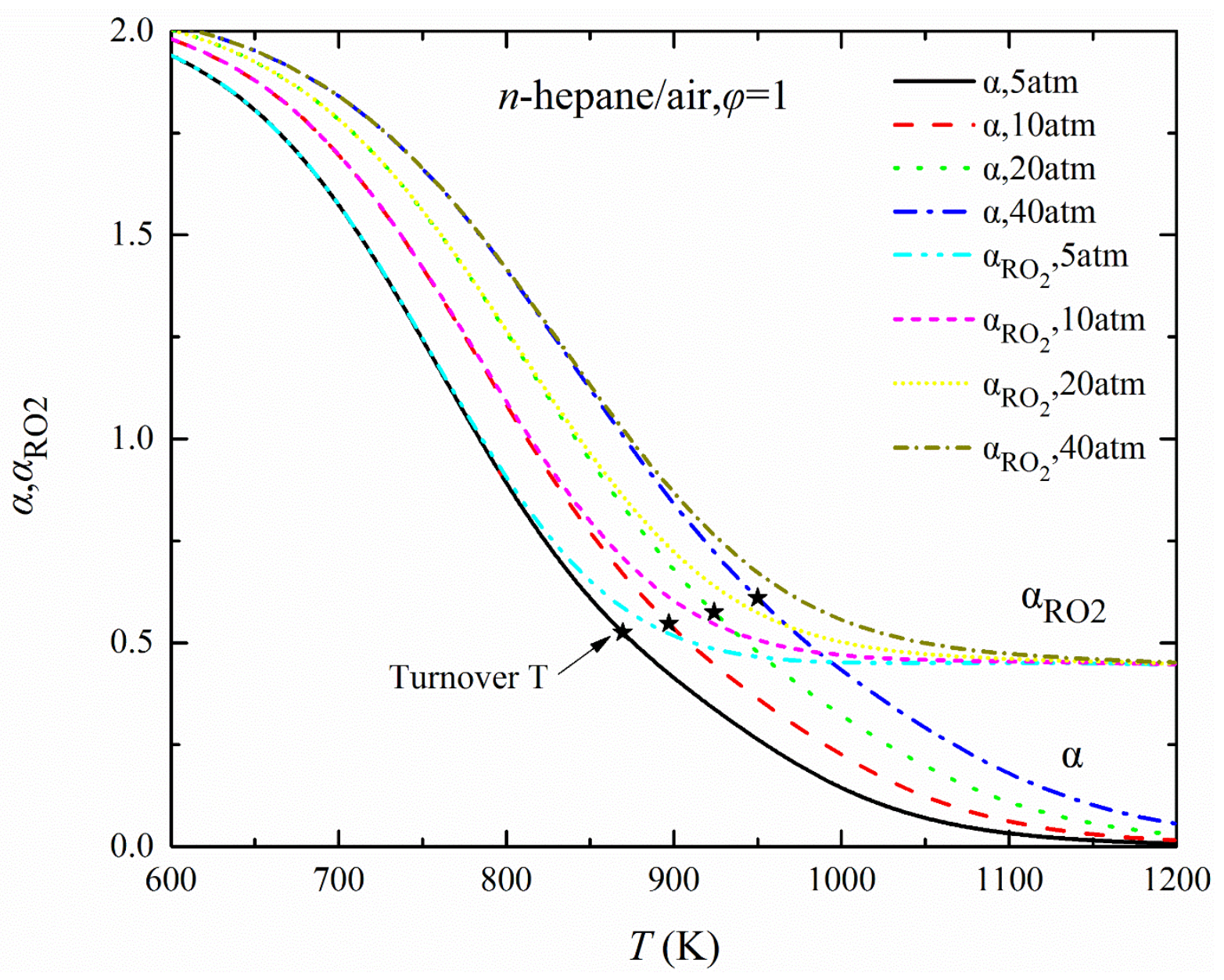

(b) 


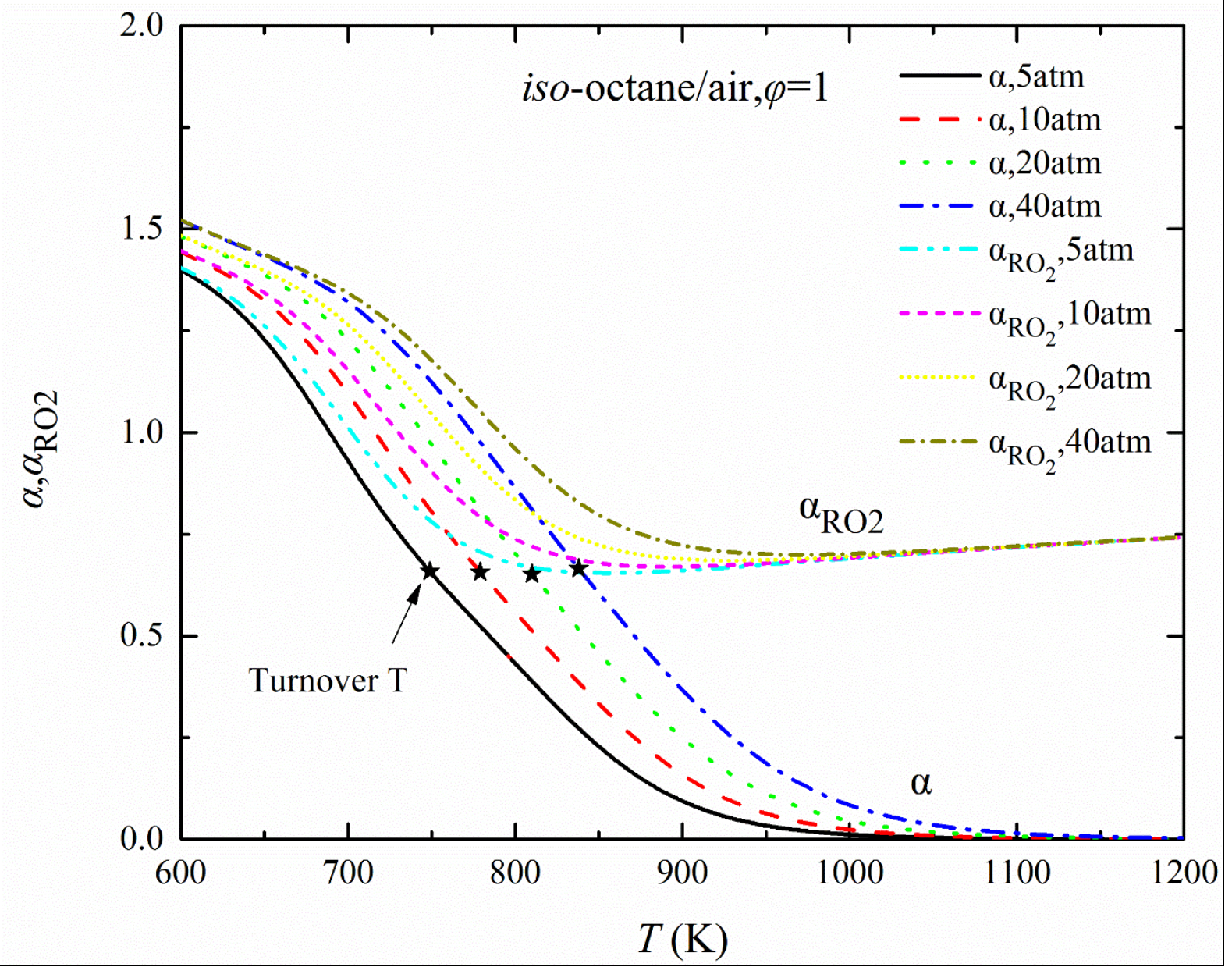

(c) different fuels. 


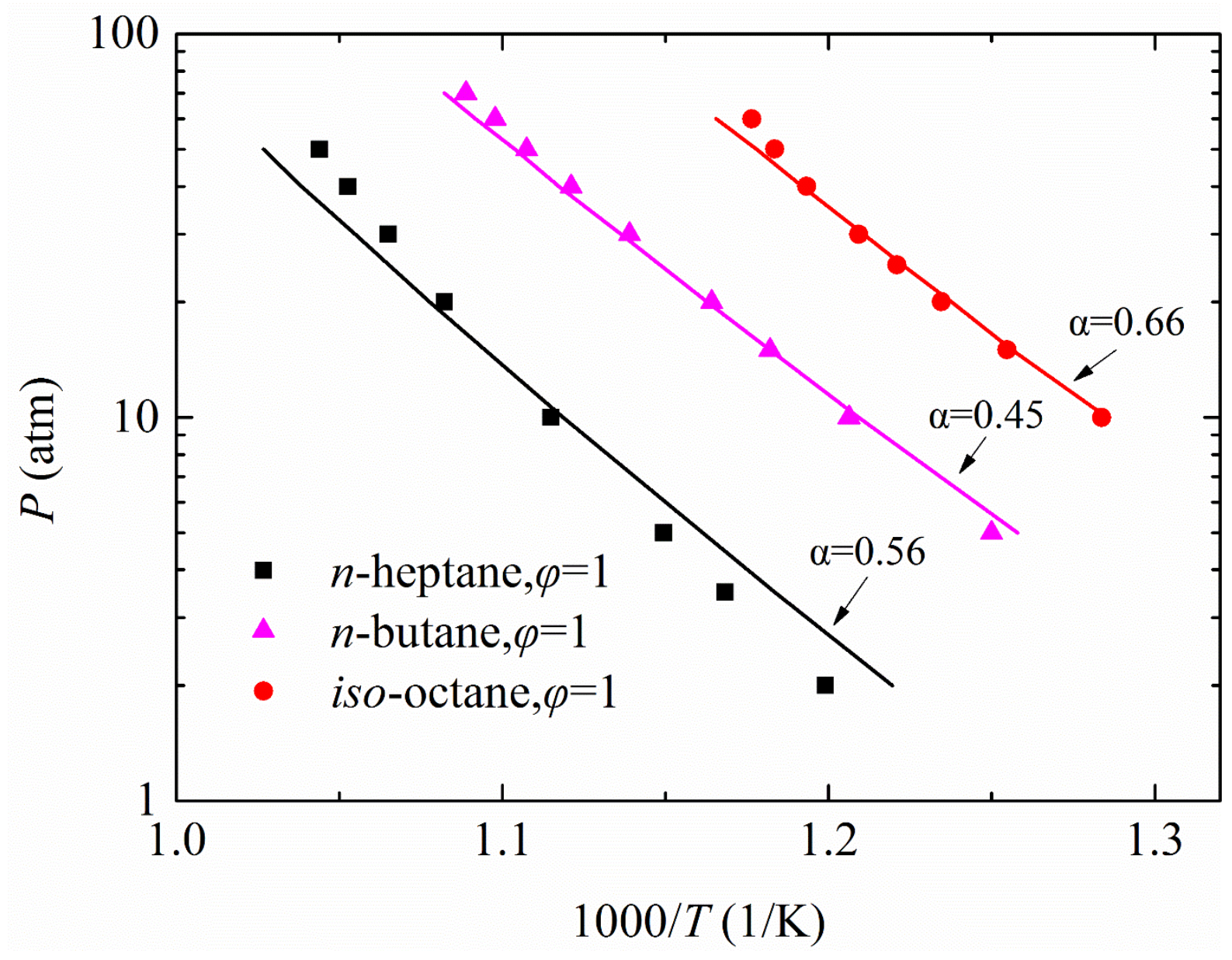

Fig. 10. Turnover temperature calculated using detailed mechanism (symbols) and obtained at a constant $\alpha$ (lines). 


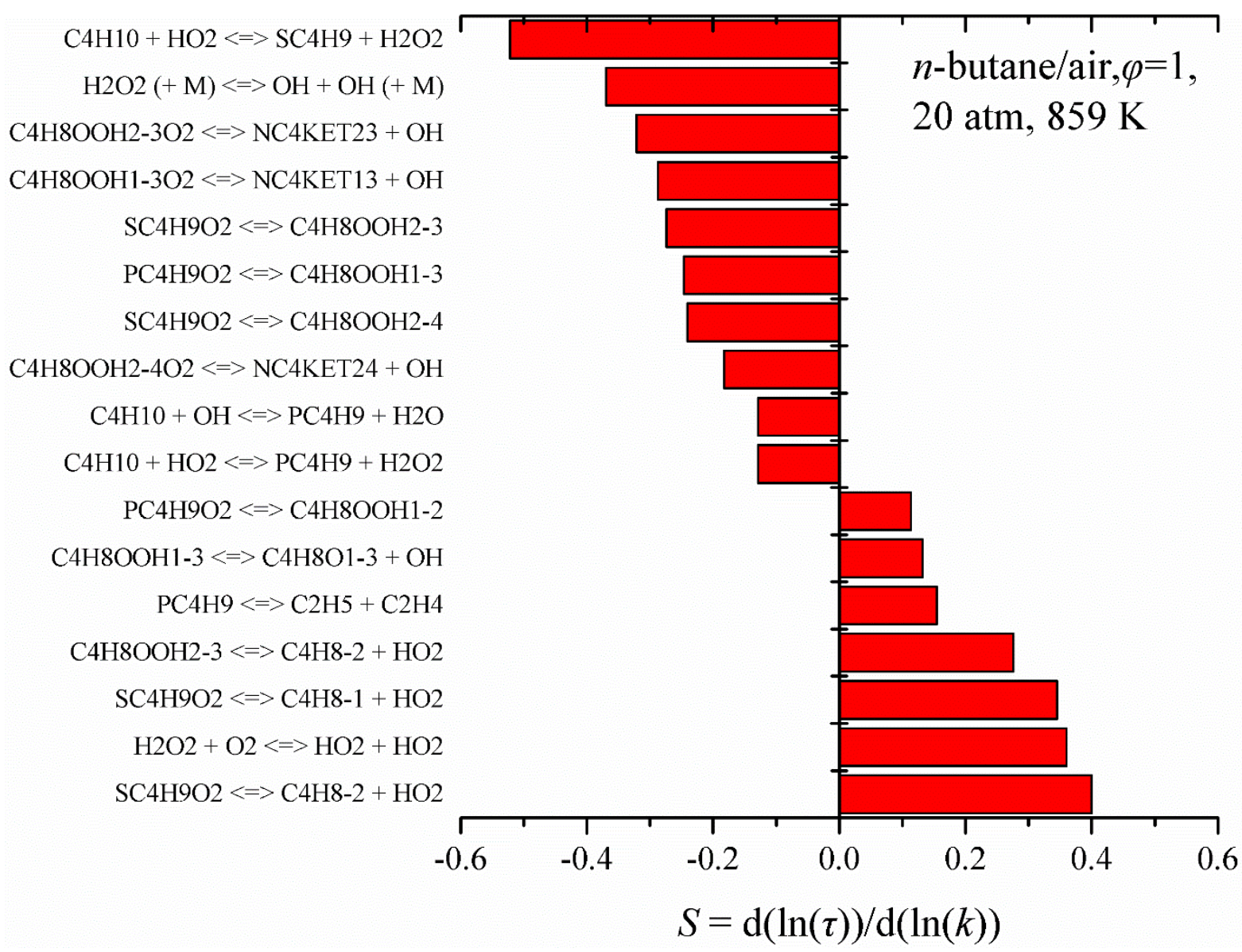

(a) 


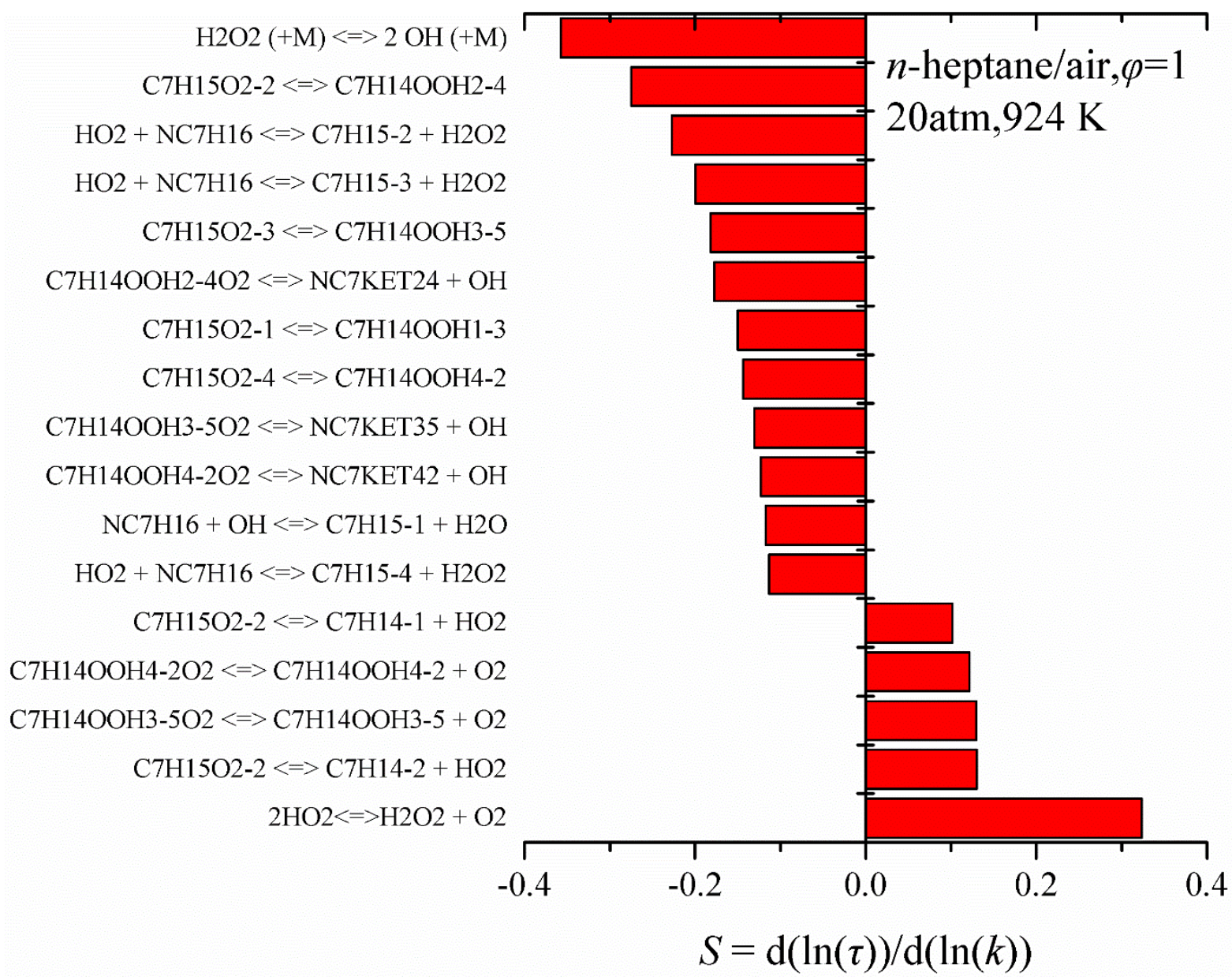

(b)

Fig. 11. The brute force sensitivity on the ignition delay at turnover temperature for $n$-butane and $n$-heptane. 


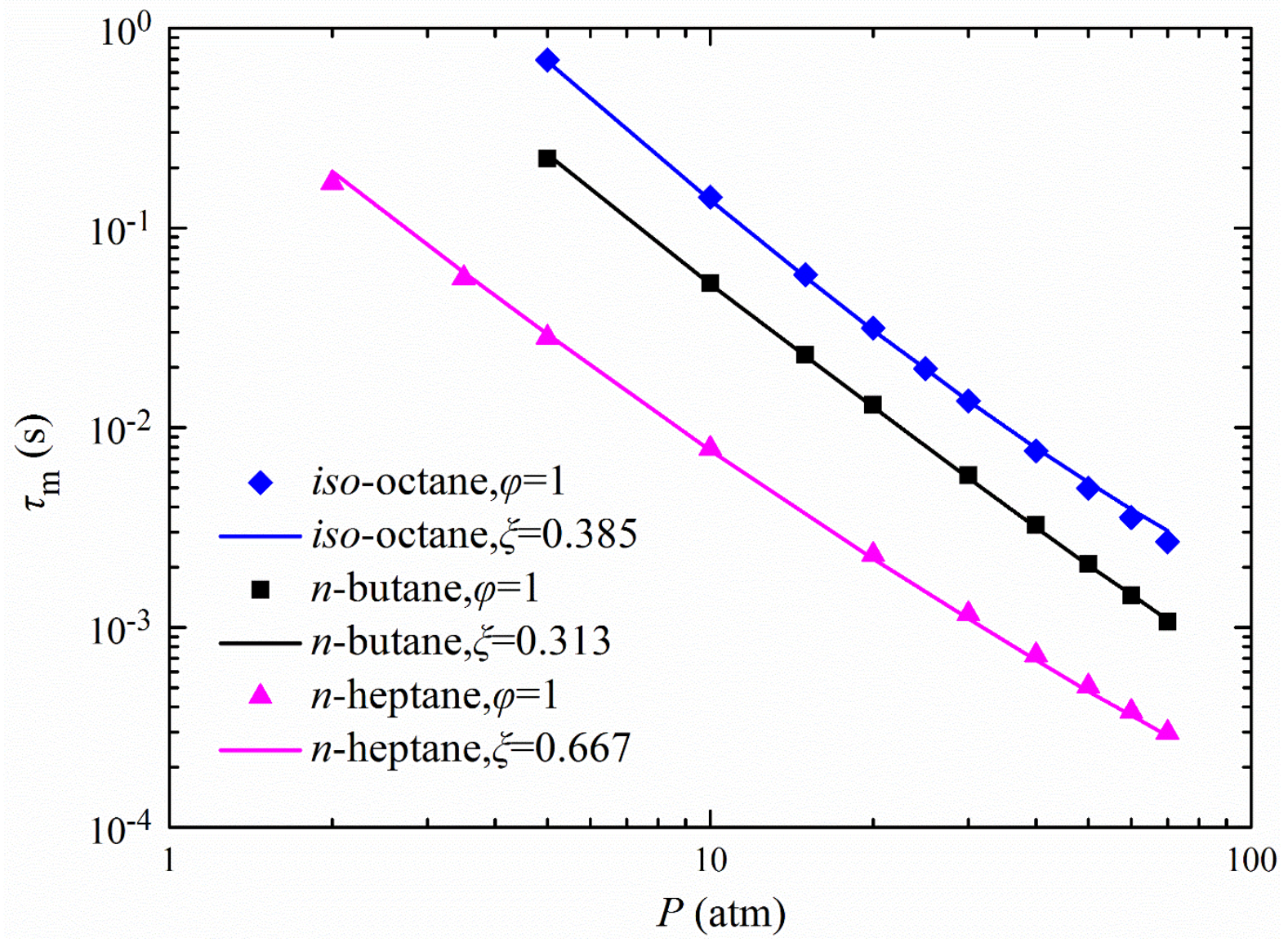

Fig. 12. The ignition delays from simulation using detailed mechanism (symbols) and from the correlation using Eq. (4). 


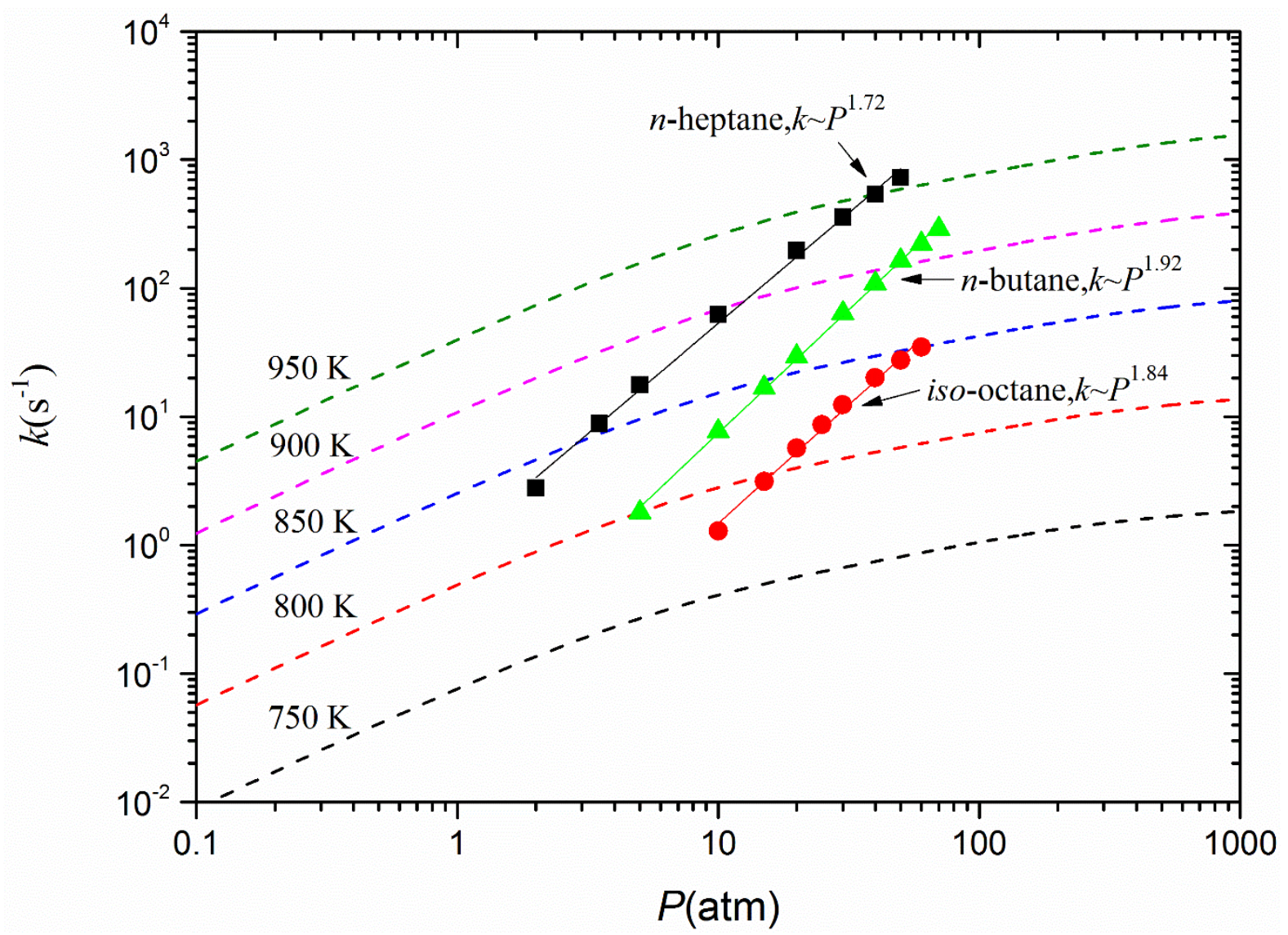

Fig. 13. The rates of $\mathrm{H}_{2} \mathrm{O}_{2}(+\mathrm{M}) \rightarrow 2 \mathrm{OH}(+\mathrm{M})$ as a function of pressure at turnover temperature for stoichiometric $n$-butane, $n$-heptane and iso-octane in air (symbols), and those rates at various temperature and pressure (dash lines). The rate constants are adopted from each detailed mechanism. 


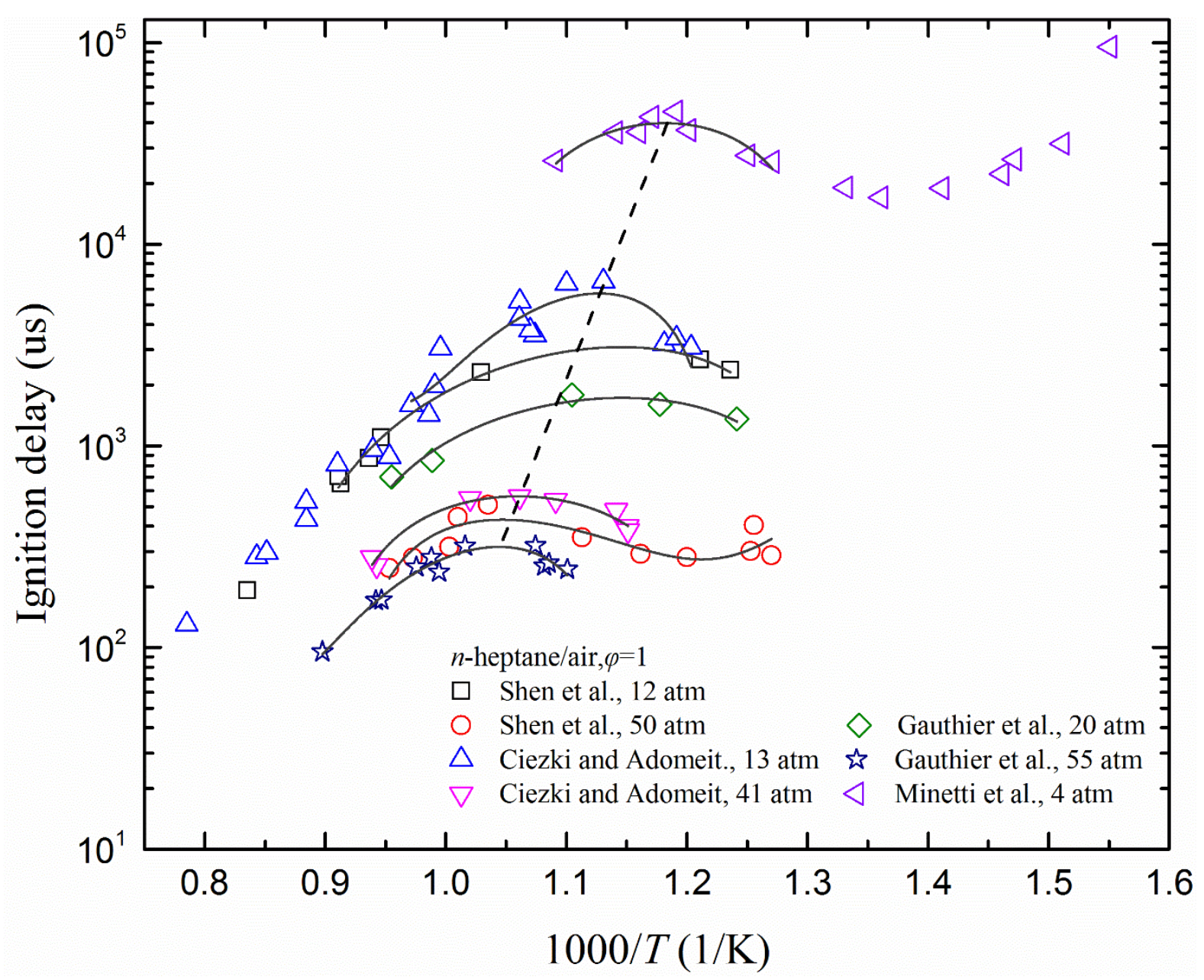

Fig. 14. Ignition delay data for stoichiometric $n$-heptane/air mixture under various pressure.

All the data are scaled to the listed pressures using $\tau \propto P^{-1}$ to account for deviations in experimental pressure [31]. Each dataset is fitted using a cubic polynomial and covering the points near turnover temperature. 


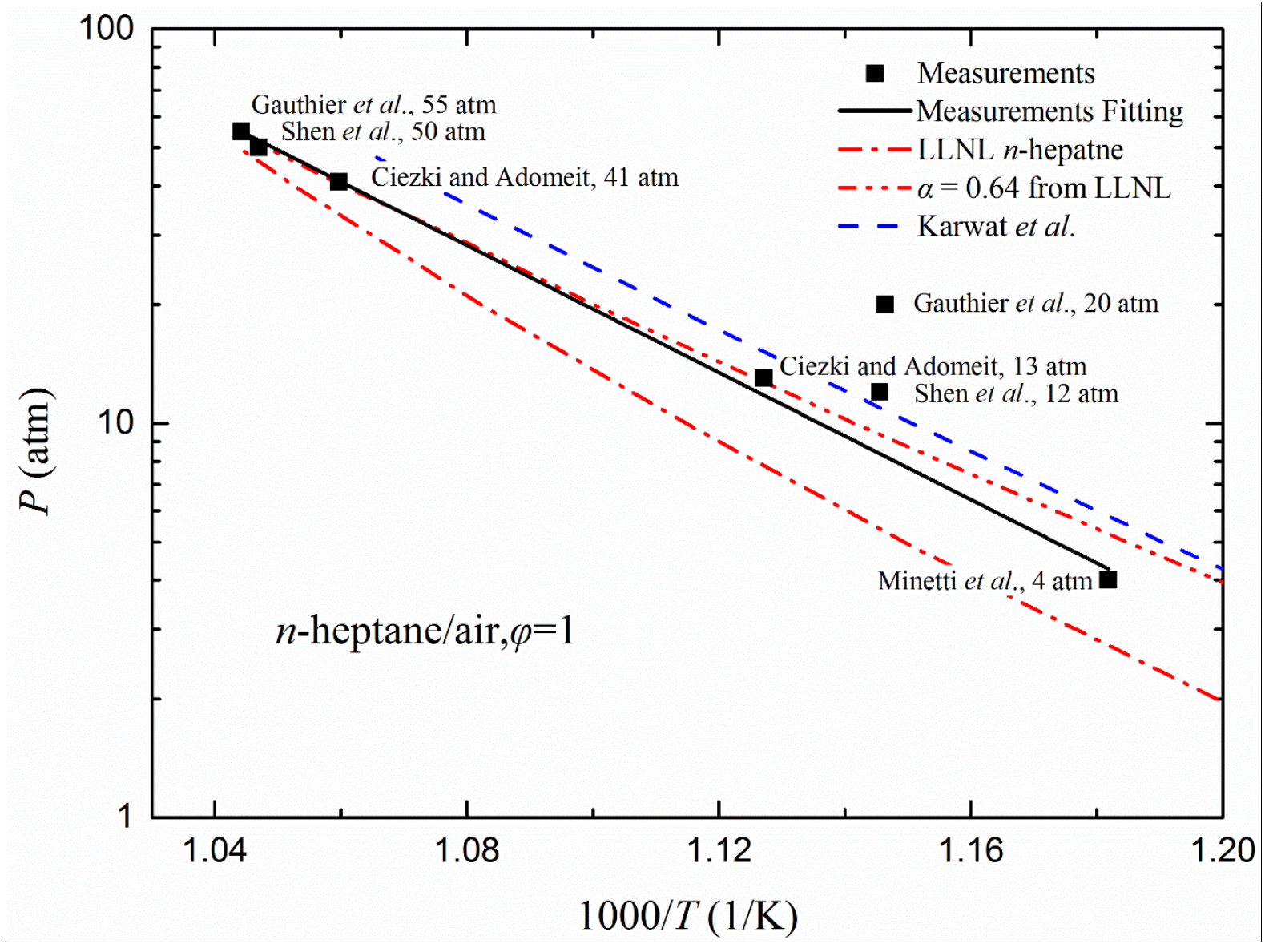

Fig. 15. The dependence of pressure on turnover temperatures for stoichiometric $n$-heptane/air mixture obtained from different methods. 


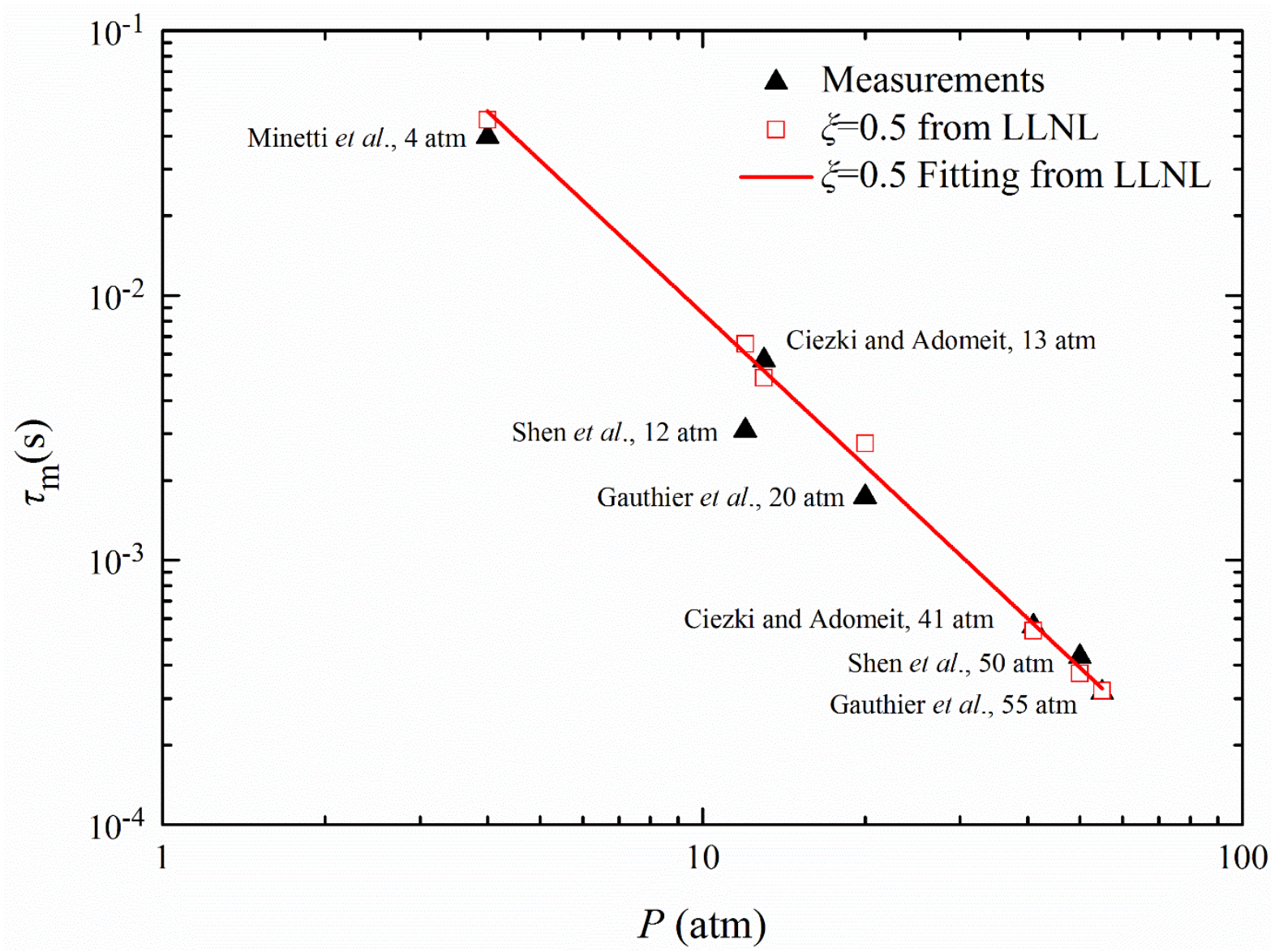

Fig. 16. The ignition delay from measurements and those from correlation using Eq. (4). 